\title{
Report on Assessment of Environmentally Assisted Fatigue for LWR Extended Service Conditions
}

Summary of

1. Room-Temperature Tensile Testing of 316 Stainless Steel Base Metal

2. Mechanistic Modeling of Crack Initiation and Crack Propagation Using Extended Finite Element Method: With Application to Steam Generator Tube Rupture Simulation

3. Other Ongoing Experimental and Mechanistic Modeling Activities Nuclear Engineering Division 
About Argonne National Laboratory

Argonne is a U.S. Department of Energy laboratory managed by UChicago Argonne, LLC under contract DE-AC02-06CH11357. The Laboratory's main facility is outside Chicago, at 9700 South Cass Avenue, Argonne, Illinois 60439. For information about Argonne and its pioneering science and technology programs, see www.anl.gov.

\section{Availability of This Report}

This report is available, at no cost, at http://www.osti.gov/bridge. It is also available on paper to the U.S. Department of Energy and its contractors, for a processing fee, from:

U.S. Department of Energy

Office of Scientific and Technical Information

P.O. Box 62

Oak Ridge, TN 37831-0062

phone (865) 576-8401

fax (865) 576-5728

reports@adonis.osti.gov

\section{Disclaimer}

This report was prepared as an account of work sponsored by an agency of the United States Government. Neither the United States Government nor any agency thereof, nor UChicago Argonne, LLC, nor any of their employees or officers, makes any warranty, express or implied, or assumes any legal liability or responsibility for the accuracy, completeness, or usefulness of any information, apparatus, product, or process disclosed, or represents that its use would not infringe privately owned rights. Reference herein to any specific commercial product, process, or service by trade name, trademark, manufacturer, or otherwise, does not necessarily constitute or imply its endorsement, recommendation, or favoring by the United States Government or any agency thereof. The views and opinions of document authors expressed herein do not necessarily state or reflect those of the United States Government or any agency thereof, Argonne National Laboratory, or UChicago Argonne, LLC. 


\section{Report on Assessment of Environmentally Assisted Fatigue for LWR Extended Service Conditions}

Summary of

1. Room-Temperature Tensile Testing of 316 Stainless Steel Base Metal

2. Mechanistic Modeling of Crack Initiation and Crack Propagation Using Extended Finite Element Method: With Application to Steam Generator Tube Rupture Simulation

3. Other Ongoing Experimental and Mechanistic Modeling Activities

prepared by

Subhasish Mohanty, William K. Soppet, Saurin Majumdar, and Ken Natesan Nuclear Engineering Division Argonne National Laboratory 
This page intentionally left blank 


\section{ABSTRACT}

This report provides an update on an earlier assessment of environmentally assisted fatigue for light water reactor (LWR) materials under extended service conditions. This quarterly report is a deliverable in FY13 under the work package for environmentally assisted fatigue in the Light Water Reactor Sustainability (LWRS) program. The overall objective of this LWRS project is to assess the degradation by environmentally assisted cracking/fatigue of LWR materials such as various alloy base metals and their welds used in reactor coolant system piping. This effort is to support the Department of Energy LWRS program for developing tools to predict the aging/failure mechanism and to correspondingly predict the remaining life of LWR components for anticipated 60-80 year operation. The Argonne National Laboratory work package can broadly be divided into the following tasks:

1. Development of mechanistic-based predictive model for life estimation of LWR reactor coolant system piping material (base and weld metals) subjected to stress corrosion cracking and/or corrosion fatigue

2. Performance of environmentally assisted cracking/fatigue experiments to validate and/or complement the activities on mechanistic model development.

There are a number of subtasks under the above-mentioned major tasks. In the reporting period of January-March 2013, the following two subtasks were completed:

a) Room-temperature tensile testing of 316 stainless steel base metal: Tensile tests were conducted on a heat-treated 316 stainless steel base metal at two strain rates. The details are described in Section 2. The same heat treatment will be used for future test specimens.

b) Evaluation of advance finite element concepts, such as extended finite element method, to model moving cracks: As described in Section 3, multiple models were developed to calculate crack propagation in steam generator tubes under accident conditions. Calculated results were validated against multiple experimental results available through the Nuclear Regulatory Commission-sponsored tube integrity program being conducted at ANL.

The report also summarizes other ongoing subtasks through some representative examples. These are discussed in Section 4. 
This page intentionally left blank 


\section{TABLE OF CONTENTS}

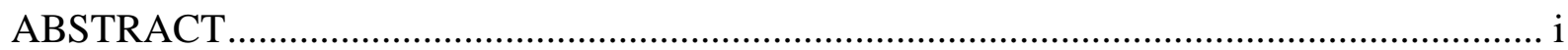

Table of Contents ................................................................................................ iii

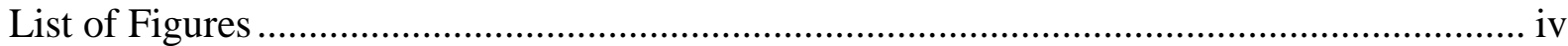

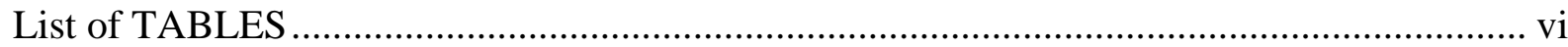

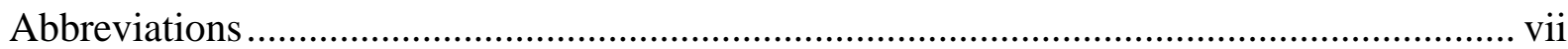

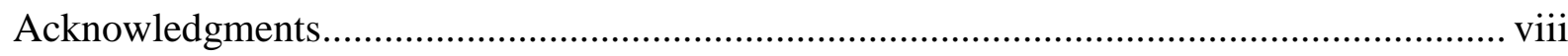

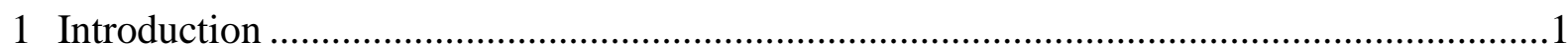

2 Room-Temperature Tensile Testing of 316 Stainless Steel Base Metal .............................3

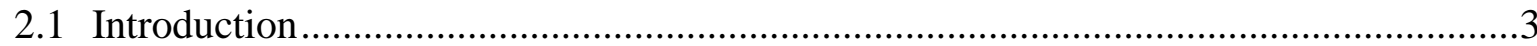

2.2 Heat information and material composition of 316 SS base metal..............................3

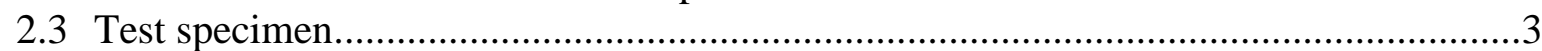

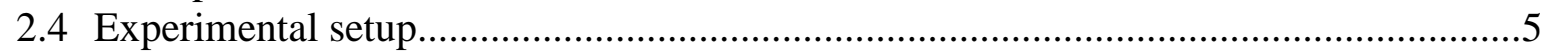

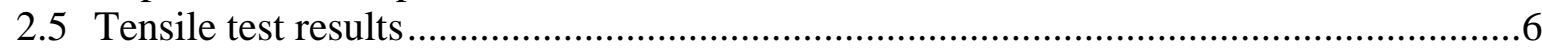

2.5.1 Stress-strain curve based on extensometer and load cell measurements..............6

2.5.2 Stress-strain curve based on actuator/crosshead position and load cell

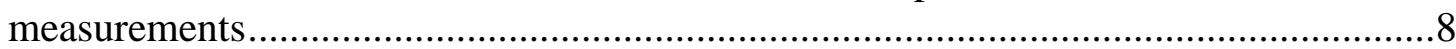

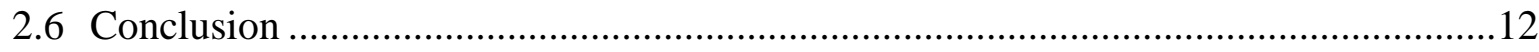

3 Mechanistic Modeling of Crack Initiation and Crack Propagation Using XFEM ...............13

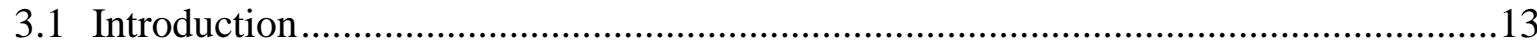

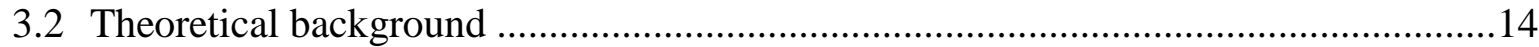

3.2.1 Extended finite element method: Generic theoretical background ...................14

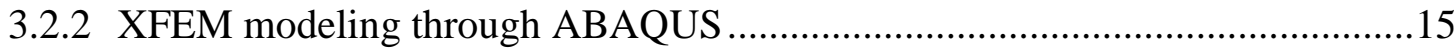

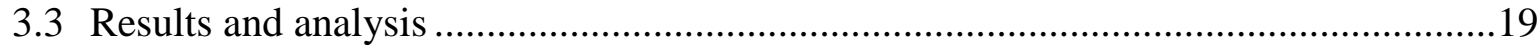

3.3.1 SG tube model with single initial crack ...................................................19

3.3.2 SG tube model with two initial cracks for crack coalescence simulation ..........25

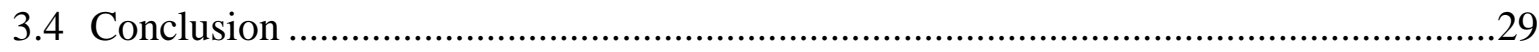

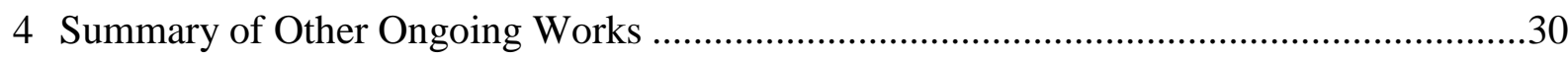

4.1 Room-temperature fatigue testing of 316 SS base metal .......................................30

4.2 Mechanistic modeling of room-temperature fatigue of 316 SS base metal .................30

4.3 Fabrication of specimen with similar metal weld plates..........................................32

4.4 Characterization and modeling of similar metal weld residual stress.........................32

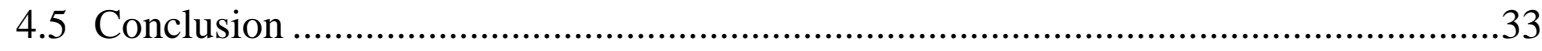

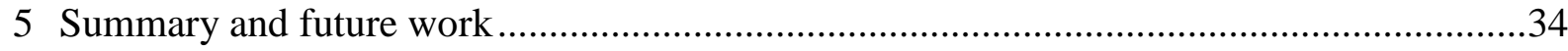

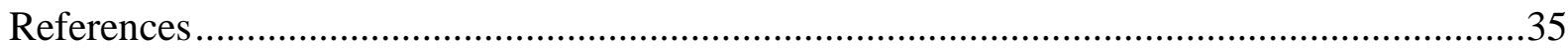




\section{LIST OF FIGURES}

Figure 2.1 Cutting plane with respect to plate rolling direction for hourglass specimen .......... 4

Figure 2.2 Geometry of the 316 SS tensile/fatigue specimen................................................ 4

Figure 2.3 Fabricated 316 SS tensile/fatigue specimen ............................................. 4

Figure 2.4 In-air tensile/fatigue test frame with specimen and various instruments .................5

Figure 2.5 Strain-versus-stress plot estimated from measurements of extensometer and load cell.

Figure 2.6 Strain-versus-stress plot showing estimated elastic modulus and $0.2 \%$ offset yield stress for tensile test at $0.0001 / \mathrm{s}$ strain rate.

Figure 2.7 Strain-versus-stress plot showing estimated elastic modulus and $0.2 \%$ offset yield stress for tensile test at $0.001 / \mathrm{s}$ strain rate.

Figure 2.8 Crosshead displacement (stroke) versus stress ............................................ 8

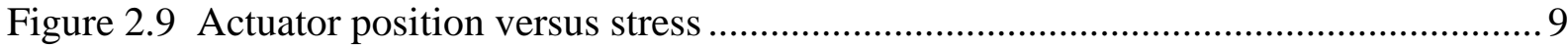

Figure 2.10 Crosshead displacement (stroke) with respect to known strain......................... 10

Figure 2.11 Actuator position with respect to known strain ........................................... 10

Figure 2.12 Strain-versus-stress curves estimated from crosshead displacement

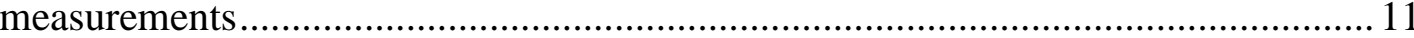

Figure 2.13 Strain-versus-stress curve estimated from actuator position measurements ....... 12

Figure 3.1 Schematic of (a) cracked and uncracked mesh showing real and phantom nodes and (b) cracked element as sum of two virtual or phantom elements...................... 16

Figure 3.2 Schematic showing the orthogonal level set fields that describe the crack tip ..... 17

Figure 3.3 Schematic of traction separation curve........................................................ 18

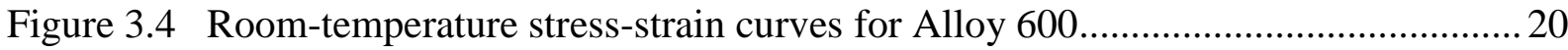

Figure 3.5 Typical FEM model of a 22.2-mm (7/8-in.) OD tube with an initial crack length of $6.35 \mathrm{~mm}$ and crack depth to wall thickness ratio of 75\%: (a) OD surface and (b) cut section of the cross section.

Figure 3.6 Maximum principal stress distribution upon exceeding the critical principal stress $\sigma_{c r}^{p}$ just before the crack initiation or cracking of the crack-tip element in

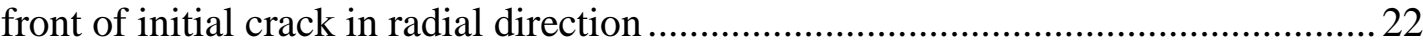

Figure 3.7 Shape of the OD surface and maximum principal stress distribution for the 22.2$\mathrm{mm}$ OD tube at (a) ID ligament rupture pressure (37.5 MPa) and (b) final burst

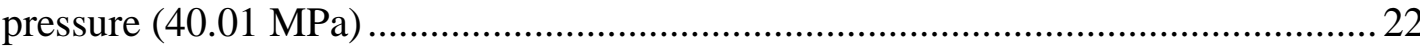

Figure 3.8 After burst shape of a typical 22.2-mm diameter tube with $6.35 \mathrm{~mm}$ initial notch: (a) top view and (b) side view

Figure 3. 9 Estimated COD with respect to applied pressure at the OD and ID surface of the 22.2-mm OD tube

Figure 3. 10 Estimated equivalent plastic strain with respect to applied pressure at radial crack-tip element (in front of the initial crack) and central ID ligament element of the 22.2-mm OD tube 
Figure 3. 11 Radial crack initiation pressure and ID ligament rupture pressure with respect to different ratios of initial crack depth to wall thickness

Figure 3. 12 Radial or wall thickness crack initiation pressure and ID ligament rupture pressure with respect to different initial crack length ......................................... 25

Figure 3. 13 FEM model of 22.2-mm (7/8-in.) OD tube with two interacting initial cracks ... 26

Figure 3. 14 Shape of the OD surface and maximum principal stress distribution for case 1 at (a) ID ligament rupture pressure $(30.97 \mathrm{MPa})$ and (b) final burst pressure $(31.22$ $\mathrm{MPa})$

Figure 3. 15 Estimated COD with respect to applied pressure at the OD and ID surface for case-1 tube (see Table 3.2) with $2 \mathrm{c}+\mathrm{b}=12.7 \mathrm{~mm}, \mathrm{a} / \mathrm{h}=72$, and $\mathrm{b}=0.25 \mathrm{~mm} \ldots \ldots .27$

Figure 3. 16 Estimated equivalent plastic strain with respect to applied pressure at the OD and ID surface for case- 1 tube (see Table 3.2) with $2 \mathrm{c}+\mathrm{b}=12.7 \mathrm{~mm}, \mathrm{a} / \mathrm{h}=72$, and $\mathrm{b}=0.25 \mathrm{~mm}$

Figure 3. 17 Distribution of equivalent plastic strain at 30.97 MPa (radial ligament rupture pressure) for case- 1 tube (see Table 3.2) with $2 \mathrm{c}+\mathrm{b}=12.7 \mathrm{~mm}, \mathrm{a} / \mathrm{h}=72$, and $\mathrm{b}=$ $0.25 \mathrm{~mm}$ .28

Figure 4.1 Extensometer-measurement-based hysteresis plot at the start and end of test......30

Figure 4.2 Finite element model of the 316 SS specimen showing preliminary results of accumulated effective plastic strain (absolute scale) field distribution ....

Figure 4.3 Hysteresis plot estimated from a preliminary FEM model assuming stress hardening 31

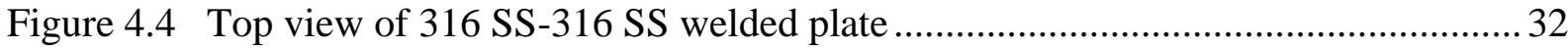

Figure 4.5 Cross section of 316 SS-316 SS welded plate.................................................. 32

Figure 4.6 Example of residual stress profile at the 316SS-316SS plate weld cross section 33 


\section{LIST OF TABLES}

Table 2. 1 Chemical composition of Type 316 SS base metal (heat P91576) .................... 3

Table 2. 2 Estimated effective gauge length and specimen nominal gauge length ................. 11

Table 2.3 Estimated material properties of $316 \mathrm{SS}$ base metal at room temperature ............ 12

Table 3.1 Room-temperature material properties for Alloy 600 ....................................... 19

Table 3.2 XFEM and experimental results for three cases of crack coalescence model ....... 29 


\section{ABBREVIATIONS}

$\begin{array}{ll}\text { ANL } & \text { Argonne National Laboratory } \\ \text { CF } & \text { Corrosion Fatigue } \\ \text { COD } & \text { Crack Opening Displacement } \\ \text { DOE } & \text { Department of Energy } \\ \text { DOF } & \text { Degrees of Freedom } \\ \text { FEM } & \text { Finite Element Method } \\ \text { ID } & \text { Inner Diameter } \\ \text { LSM } & \text { Level Set Method } \\ \text { LWR } & \text { Light Water Reactor } \\ \text { LWRS } & \text { Light Water Reactor Sustainability } \\ \text { NRC } & \text { Nuclear Regulatory Commission } \\ \text { OD } & \text { Outer Diameter } \\ \text { PUM } & \text { Partition of Unity Method } \\ \text { RT } & \text { Room Temperature } \\ \text { SCC } & \text { Stress Corrosion Cracking } \\ \text { SS } & \text { Stainless Steel } \\ \text { SG } & \text { Steam Generator } \\ \text { XFEM } & \text { Extended Finite Element Method }\end{array}$




\section{ACKNOWLEDGMENTS}

This research was sponsored by the U.S. Department of Energy, Office of Nuclear Energy, for the Light Water Reactor Sustainability Research and Development effort, under the program manager Dr. Jeremy Busby. 


\section{Introduction}

The objective of this project, in support of the Light Water Reactor Sustainability (LWRS) program, is to assess the degradation by environmentally assisted cracking/fatigue of LWR piping materials, such as various alloy base metals and their welds. This effort is to support the Department of Energy LWRS program for developing tools to predict the aging mechanism and associated remaining life of LWR components, including the reactor pressure vessel, for anticipated 60-80 year operation.

The program started in January 2012. Two major tasks are associated with this program, as summarized below:

\section{Task 1: Development of mechanistic-based predictive model}

In this task, physics/mechanics-based finite element models will be developed. This task has the following tentative subtasks.

Task 1.1: Modeling of moving crack initiation and propagation by using advanced finite element tools such as extended finite element method (XFEM)

Task 1.2: Modeling of in-air mechanical fatigue of base metal and similar and dissimilar metal weld geometry under pure mechanical (e.g., LWR pressure cycle) loading at room temperature

Task 1.3: Modeling of in-air thermo-mechanical fatigue of base metal and similar and dissimilar metal weld geometry under thermal-mechanical cyclic loading at LWR operating temperature

Task 1.4: Modeling of thermo-mechanical-chemical stress corrosion cracking (SCC) of base metal and similar and dissimilar metal weld geometry under both thermal and pressure cycle loading in LWR environment

Task 1.5: Modeling of thermo-mechanical-chemical corrosion fatigue (CF) of base metal and similar and dissimilar metal weld geometry under both thermal and pressure cycle loading in LWR environment

Task 2: Experimental validation and development of empirical predictive model

In this task, limited experiments will be performed to validate/complement the above task on development of mechanistic-based predictive models. This second task has the following tentative subtasks.

Task 2.1: Material procurement and fabrication of base metal and similar and dissimilar weld metal specimens

Task 2.2: In-air tensile testing at room temperature of base metal and similar and dissimilar metal weld specimens

Task 2.3: In-air tensile testing at LWR operating temperature of base metal and similar and dissimilar metal weld specimens

Task 2.4: In-air fatigue testing at room temperature of base metal and similar and dissimilar weld metal specimens

Task 2.5: In-air fatigue testing at LWR operating temperature of base metal and similar and dissimilar metal weld specimens 
Task 2.6: SCC testing under LWR conditions of base metal and similar and dissimilar metal weld specimens

Task 2.7: Fatigue (Corrosion-fatigue) testing under LWR conditions of base metal and similar and dissimilar metal weld specimens

This quarterly report highlights some of the completed and ongoing research efforts. The report is divided into the following sections:

Section 1 - Introduction: This section briefly describes the objective of the LWRS program with some tentative planned tasks.

Section 2 - Room-Temperature Tensile Testing of 316 Stainless Steel Base Metal: This section describes the details of the room-temperature tensile tests of 316 stainless steel (SS) base metal. This section gives baseline material properties for both developing a mechanistic model and selecting test parameters for future tensile/fatigue experiments.

Section 3 - Mechanistic Modeling of Crack Initiation and Crack Propagation using XFEM: This section describes the theoretical background of the extended finite element approach that can be used to model a moving crack. The approach is demonstrated through crack initiation and propagation modeling of steam generator tubes. The calculated results are compared with the experimental results available through the NRCsponsored steam generator tube integrity program conducted at Argonne National Laboratory (ANL).

Section 4 - Summary of Other Ongoing Tasks: This section describes the various ongoing tasks related to mechanistic modeling and experimental activities. These activities are discussed briefly with some preliminary results.

Section 5 - Summary and Future Work 


\section{Room-Temperature Tensile Testing of 316 Stainless Steel Base Metal}

\subsection{Introduction}

Room-temperature tensile tests are needed for both 316 SS and 508 low carbon steel base materials to establish the baseline material behavior, such as stress-strain curve, yield stress, and ultimate stress. Based on these baseline behaviors, the test parameters for room temperature fatigue and, subsequently, the parameters for environmental fatigue tests will be determined. In addition, these room-temperature material properties can be used for mechanistic modeling through finite element simulation. To date, the room-temperature tensile tests have been completed for $316 \mathrm{SS}$, which is the base metal for all weldments in our study, as discussed in the following subsections. Tests were conducted at two strain rates, $0.0001 / \mathrm{s}(0.01 \% / \mathrm{s})$ and a higher rate of $0.001 / \mathrm{s}(0.1 \% / \mathrm{s})$. Note that, although the room-temperature tensile material properties of 316 SS are available in the literature, they may not be representative of the particular heat and material composition of the ANL fatigue specimens.

\subsection{Heat information and material composition of 316 SS base metal}

The 316 SS specimens used in the current work were fabricated from 316 SS plate stored in ANL's material repository. The plate was originally procured from Eastern Stainless Company (currently closed) in 1979. As described by the manufacturer, the plate was water quenched and mill annealed at $1900{ }^{\circ} \mathrm{F}$. The heat number for the material is P91576, and the corresponding chemical composition is given in Table 2.1.

Table 2. 1 Chemical composition of Type 316 SS base metal (heat P91576)

\begin{tabular}{|c|c|c|c|c|c|c|c|c|c|}
\hline \multicolumn{10}{|c|}{ Chemical composition (wt\%) } \\
\hline $\mathrm{C}$ & $\mathrm{Cr}$ & $\mathrm{Cu}$ & $\mathrm{Mn}$ & $\mathrm{Mo}$ & $\mathrm{N}$ & $\mathrm{Ni}$ & $\mathrm{P}$ & $\mathrm{S}$ & $\mathrm{Si}$ \\
\hline 0.21 & 17.37 & 0.2 & 1.6 & 2.12 & 0.067 & 10.77 & 0.018 & 0.010 & 0.46 \\
\hline
\end{tabular}

\subsection{Test specimen}

Hourglass specimens conforming to ASTM standard E8/E8M [1] and E606 [2] have been fabricated for both tensile and fatigue testing of the base metal. The specimens were fabricated along the rolling direction of a 316 SS plate, as shown in Figure 2.1. The dimensions of the specimen are given in Figure 2.2. Figure 2.3 shows a photograph of the as-fabricated specimen. 


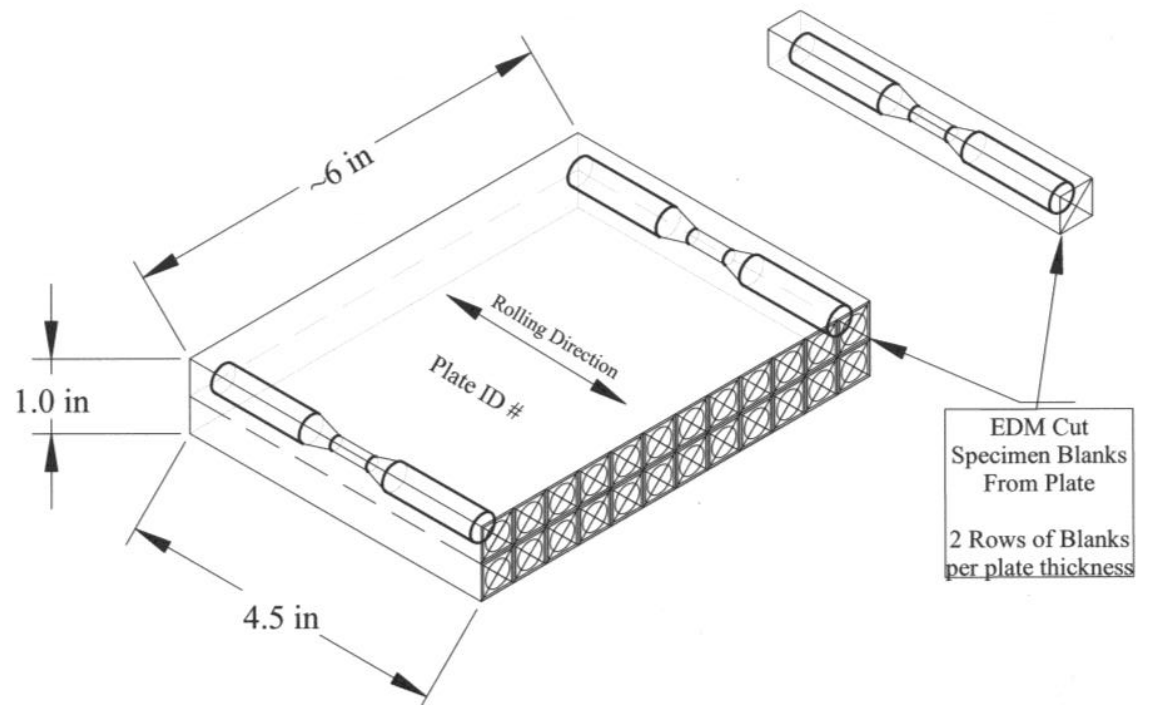

Figure 2.1 Cutting plane with respect to plate rolling direction for hourglass specimen

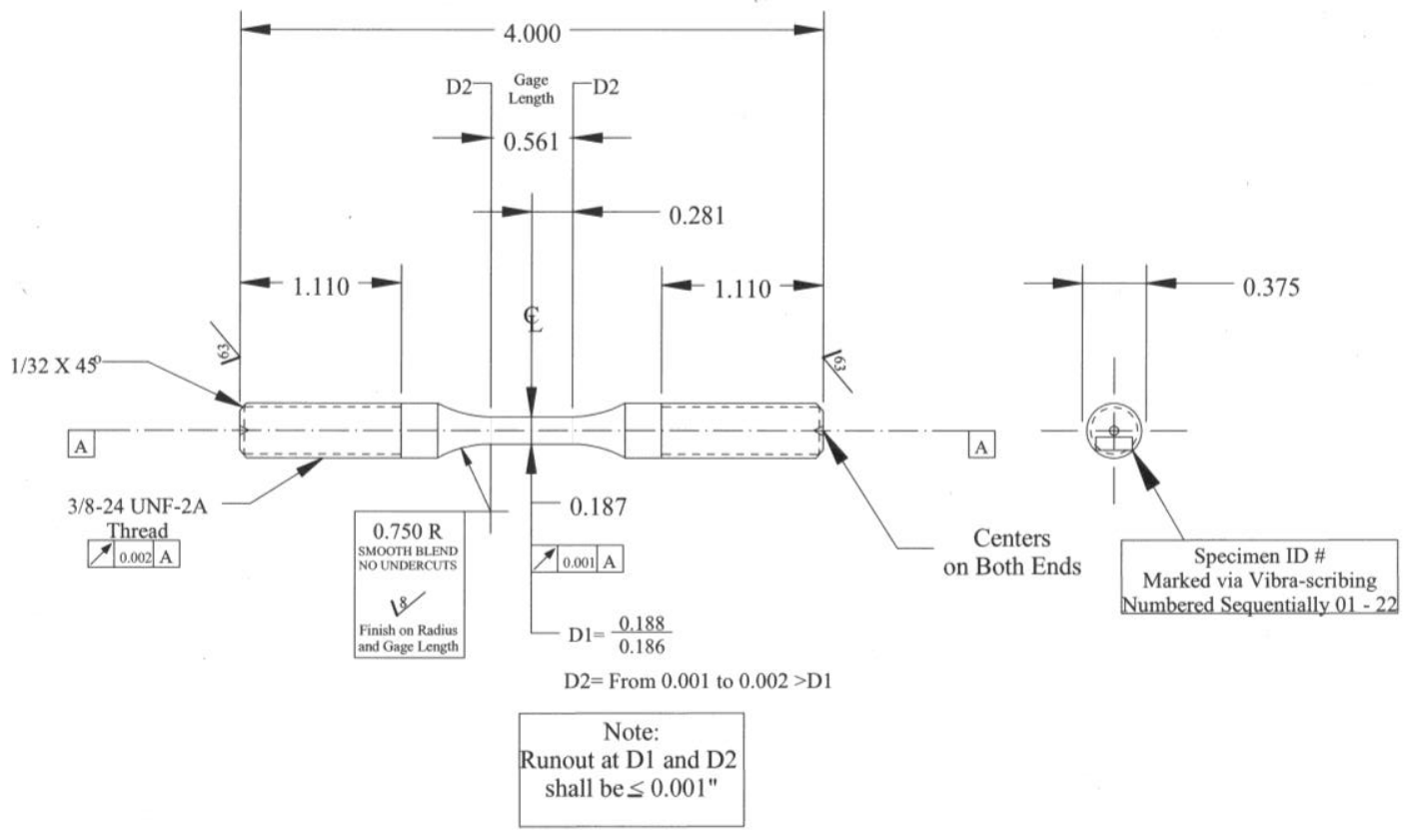

Figure 2.2 Geometry of the 316 SS tensile/fatigue specimen

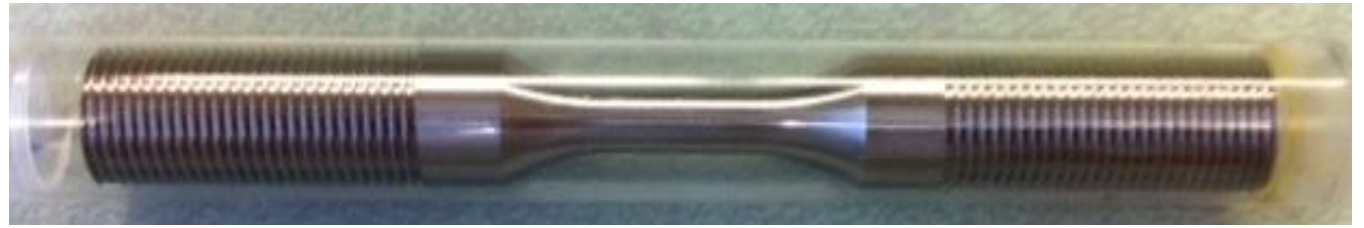

Figure 2.3 Fabricated 316 SS tensile/fatigue specimen 


\subsection{Experimental setup}

A hydraulically controlled MTS test frame was used for the tensile and fatigue tests described in this report. The test frame with the installed specimen (Figure 2.4) is instrumented to measure various parameters. In general, measurements were collected by the following builtin or added-on sensors:

a) Built-in test frame load cell

b) Built-in test frame actuator position sensor for actuator position measurement

c) Added-on displacement (stroke) sensor for crosshead position measurement

d) Added-on extensometer for strain measurement

e) Added-on ultrasonic sensor system in-house built for online/real-time structural health monitoring

For the current in-air tests, an extensometer-based strain signal is used as feedback to control the axial strain of the test specimens. However, for environmental testing it may not be feasible to insert the extensometer into the test chamber, and the controller feedback has to be obtained from either the actuator position sensor built into the test frame or the added-on crosshead displacement sensor, which can be mounted outside the environmental chamber. A different test frame with the environmental chamber is being configured at ANL's low cycle fatigue laboratory for future use in the LWRS-related environmental fatigue tests.

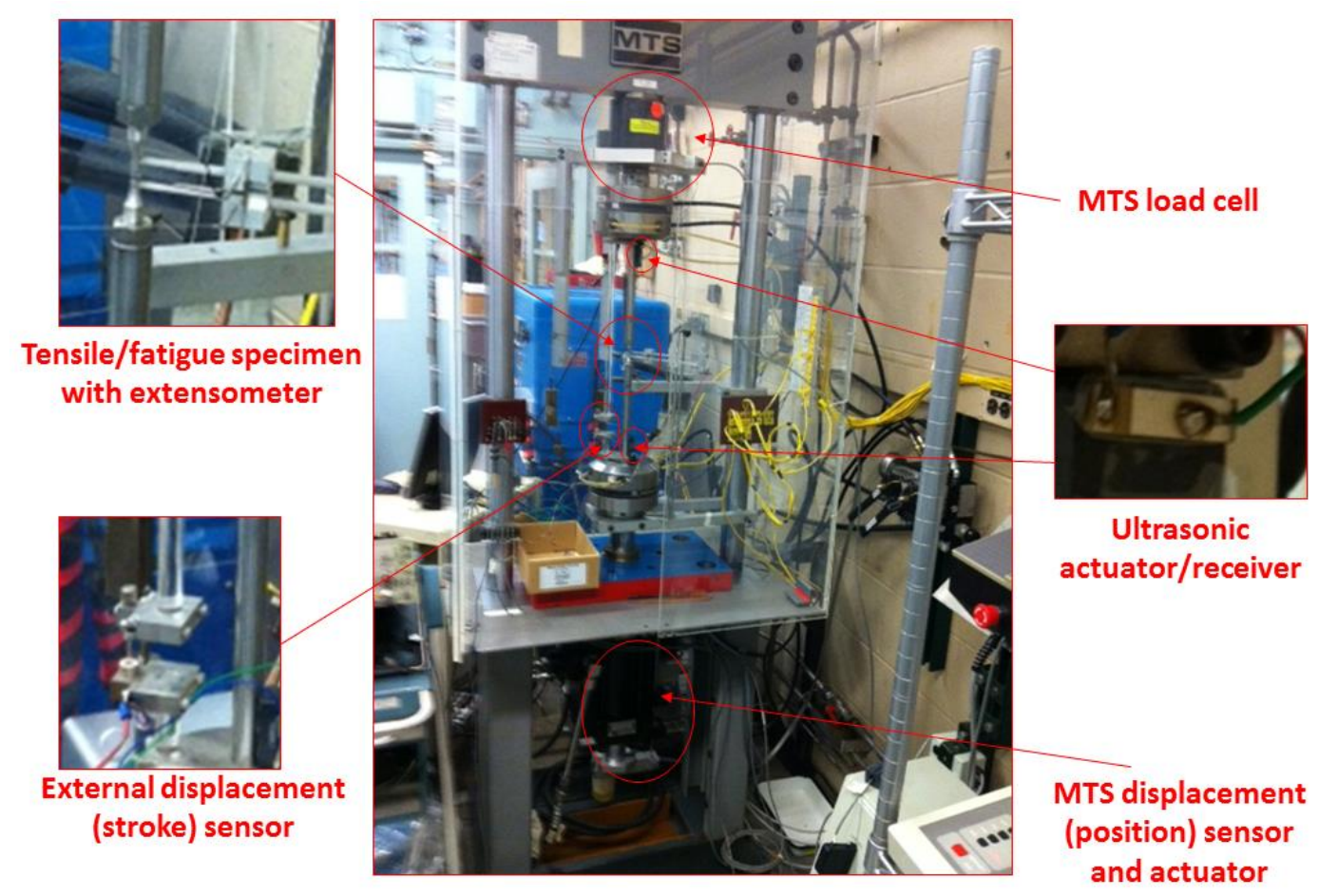

Figure 2.4 In-air tensile/fatigue test frame with specimen and various instruments 


\subsection{Tensile test results}

Tensile tests with Type 316 SS specimens were conducted in air at room temperature and two strain rates: $0.0001 / \mathrm{s}(0.01 \% / \mathrm{s})$ and $0.001 / \mathrm{s}(0.1 \% / \mathrm{s})$. The test results are described below.

\subsubsection{Stress-strain curve based on extensometer and load cell measurements}

The stress-strain curves estimated using the extensometer and load cell signal are shown in Figure 2.5. A hardening effect that is dependent on strain rate is evident in this figure. The stress curve is higher for the test specimen at the higher strain rate compared with that for the lower rate. This rate dependency of the stress evident in the tensile tests has to be included in fatigue modeling. Also, these stress-strain curves provide the elastic modulus and yield stress. The estimated elastic moduli and $0.2 \%$ offset yield stresses for strain rates of $0.0001 / \mathrm{s}$ and $0.001 / \mathrm{s}$ are plotted in Figures 2.6 and 2.7, respectively. Because of the limits of the extensometer design, these figures show the maximum strains up to $2 \%$. The same extensometer will be used for the tensile and fatigue testing at elevated temperature. This is not a serious constraint for the fatigue tests, which will generally have axial strain amplitudes $\leq 1 \%$. The strain measurement capability of the available extensometer may be more limited during elevated-temperature fatigue testing.

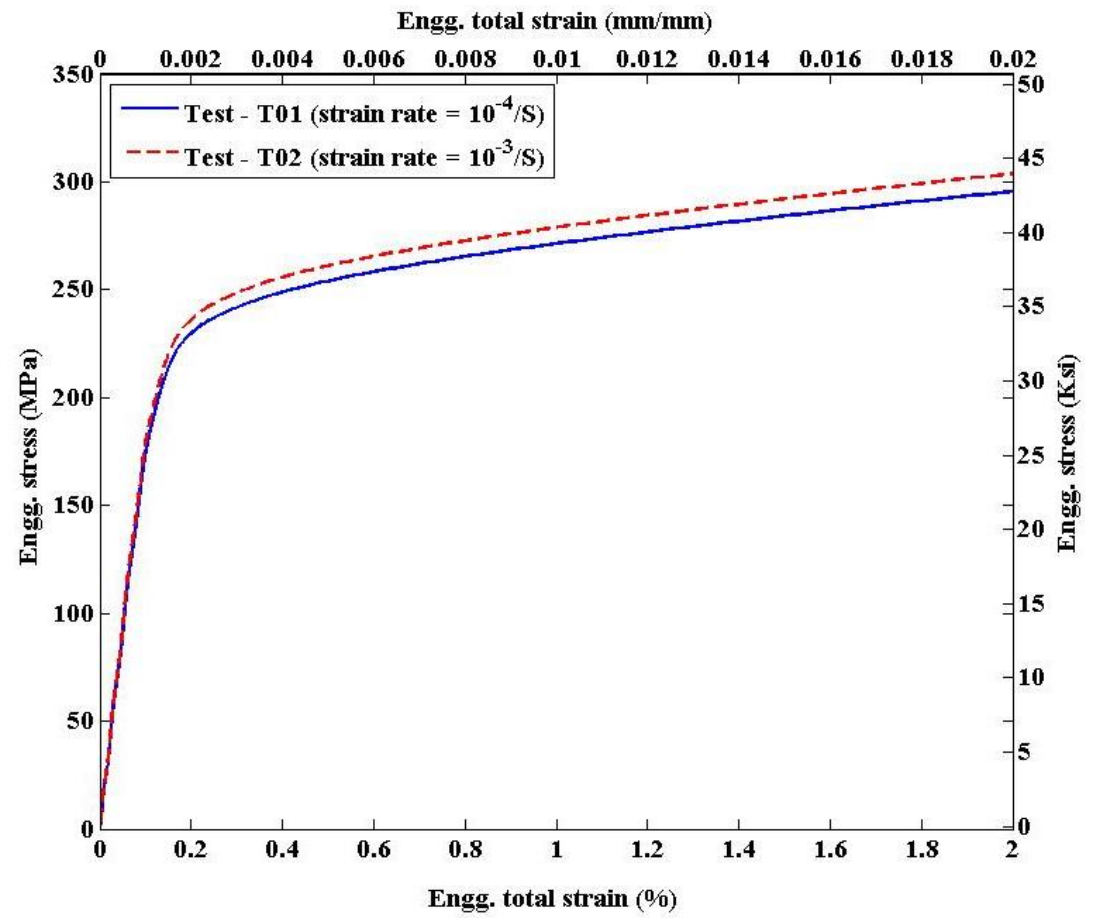

Figure 2.5 Strain-versus-stress plot estimated from measurements of extensometer and load cell 


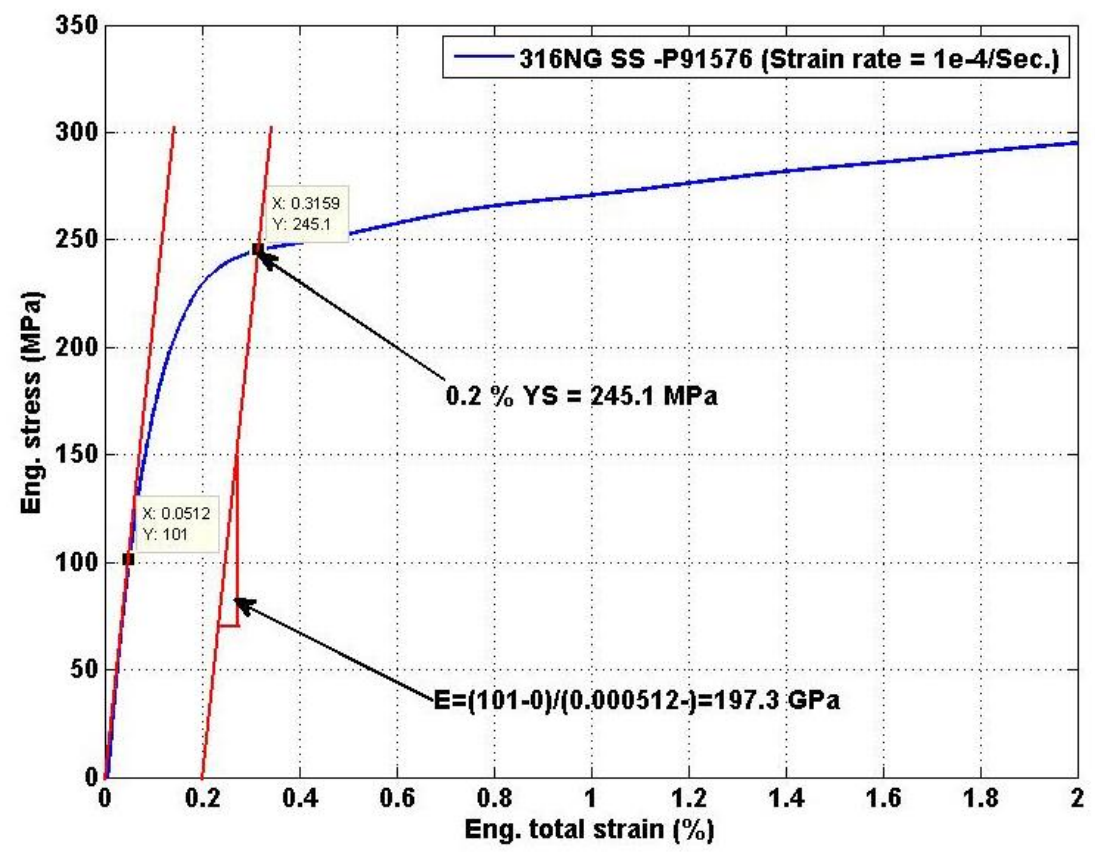

Figure 2.6 Strain-versus-stress plot showing estimated elastic modulus and $0.2 \%$ offset yield stress for tensile test at $0.0001 / \mathrm{s}$ strain rate

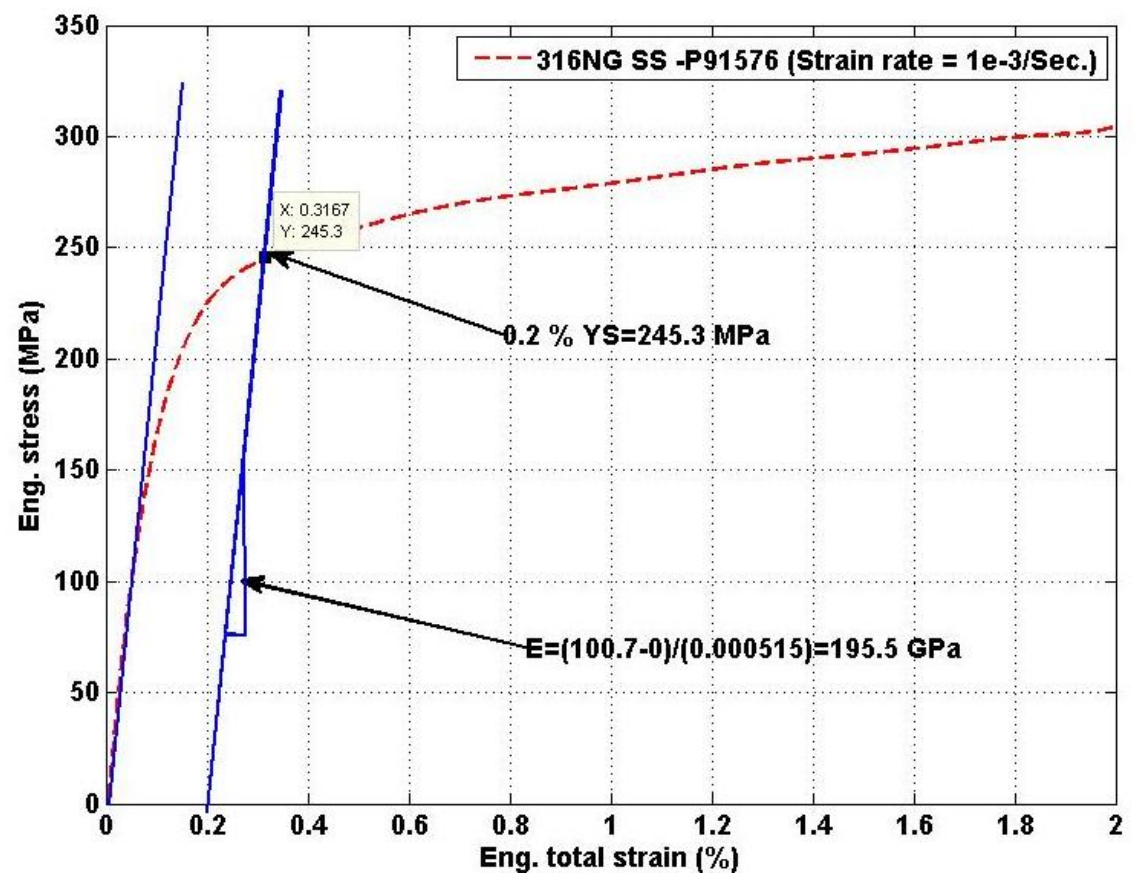

Figure 2.7 Strain-versus-stress plot showing estimated elastic modulus and $0.2 \%$ offset yield stress for tensile test at $0.001 / \mathrm{s}$ strain rate 


\subsubsection{Stress-strain curve based on actuator/crosshead position and load cell measurements}

As mentioned earlier, the extensometer used in the test has maximum strain amplitude of $2 \%$. Although this limit is adequate for strain-control fatigue testing, it may not be sufficient for use in finite element modeling, in which the locally accumulated plastic strain may exceed $2 \%$. The higher strain limit for the stress-strain curve can be estimated by using the measured displacements from the added-on crosshead position (stroke) sensor or the actuator position sensor built into the test frame. The original displacement-versus-stress curve corresponding to the measurements from the crosshead position and actuator position sensors are shown in Figures 2.8 and 2.9, respectively. Comparing these curves, we find that the crosshead displacement sensor has a more limited range. This limitation is due to the use of a ceramic displacement sensor, which has a limited measurement range of $0.635 \mathrm{~mm}(0.025 \mathrm{in}$.). Note that both the extensometer and the crosshead displacement sensor will be used for the future in-air tensile/fatigue testing at elevated temperature. However, unlike the extensometer, which cannot be inserted inside an environmental chamber for environmental fatigue testing, the crosshead position sensor is located outside the environmental chamber, and its data will be used along with a calibration curve to control the axial strain in the specimen during the future fatigue testing.

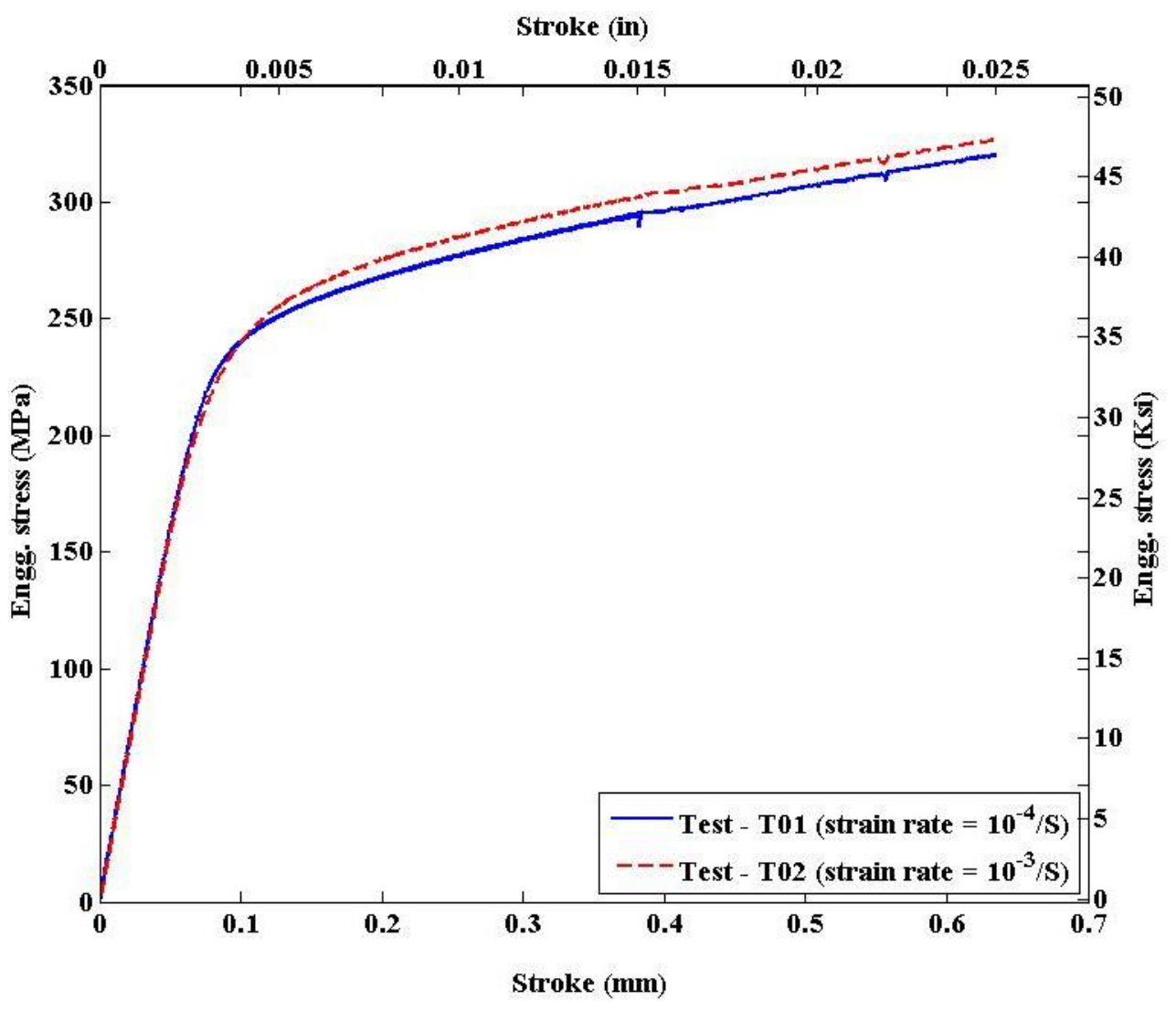

Figure 2.8 Crosshead displacement (stroke) versus stress 


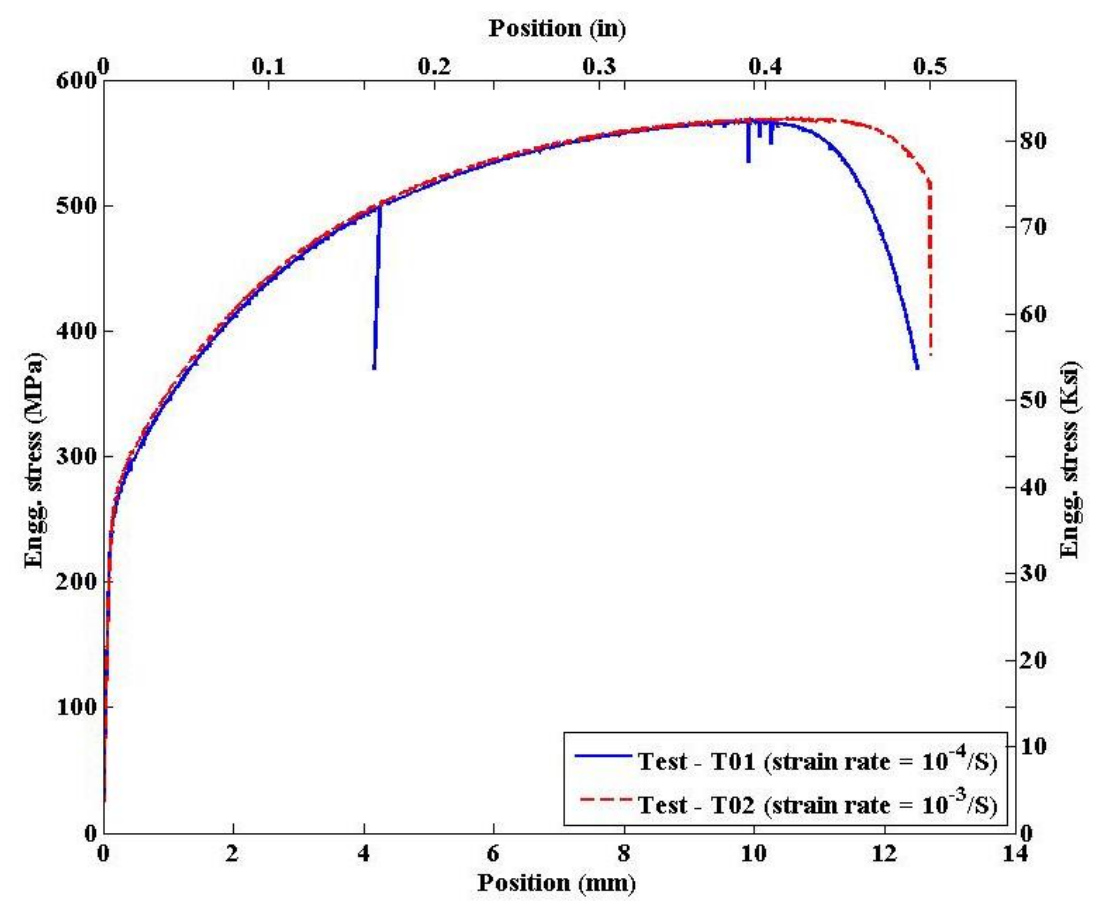

Figure 2.9 Actuator position versus stress

Figures 2.8 and 2.9 show the measured stress as a function of displacement. For input to finite element analysis, it is necessary to covert these load-displacement curves to equivalent stress-strain curves. It is also necessary to estimate the equivalent strain from measured displacement for deciding test parameters in a strain-control fatigue test where extensometer cannot be used. This estimation can be performed by mapping known displacement to known strain and then predicting unknown strains from the known displacements. For simplicity, a mapping function can be established between known displacements with known strain through least squares fitting. Using the estimated parameters of the mapping function, we can estimate the unknown strain from the known or measured displacements. The known strain at a given instant of time $\varepsilon_{t}$ can be expressed as

$$
\varepsilon_{t}=\frac{l_{t}-l_{o}}{L_{e f f}}=\left(\frac{1}{L_{e f f}}\right) l_{t}+\left(\frac{-l_{o}}{L_{e f f}}\right)
$$

where $l_{t}$ is the known or measured displacement at time $t, l_{0}$ is the initial displacement, $L_{\text {eff }}$ is the effective gauge length, and $\frac{1}{L_{e f f}}$ and $\frac{-l_{o}}{L_{e f f}}$ are the unknown parameters that can be estimated through least squares fitting. The crosshead displacement (stroke) and actuator position are plotted with respect to known strain in Figures 2.10 and 2.11, respectively. 


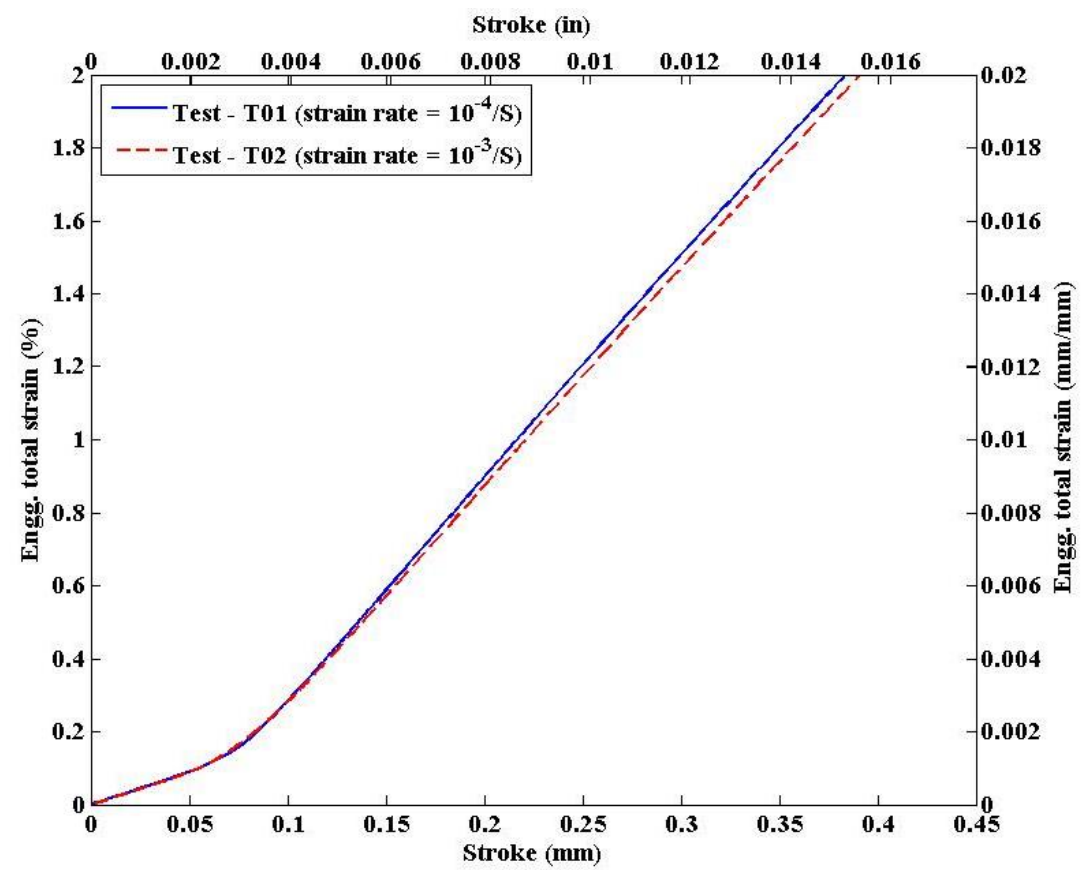

Figure 2.10 Crosshead displacement (stroke) with respect to known strain

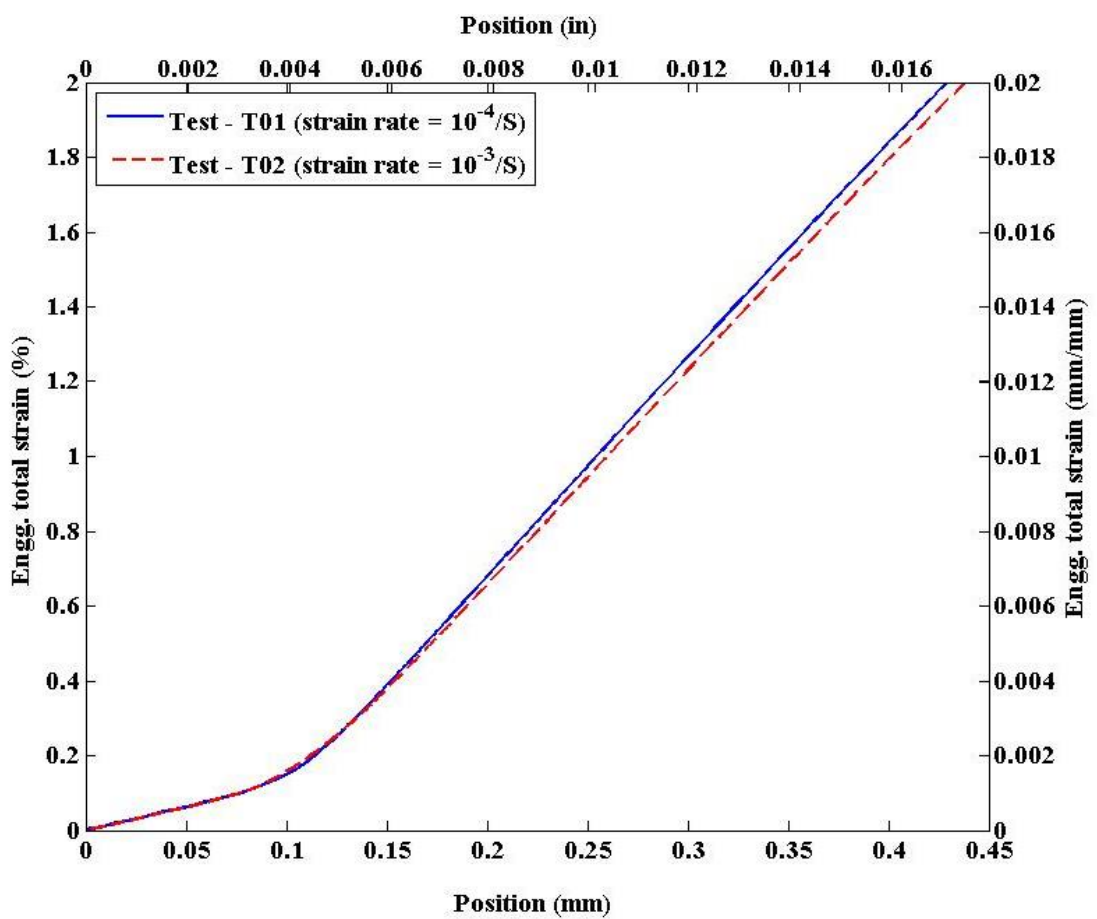

Figure 2.11 Actuator position with respect to known strain

Using Eq. 2.1 and the known crosshead and actuator position data in Figures 2.10 and 2.11, we estimated the effective length $L_{\text {eff }}$. Note that, for estimating the least squares fit, we only considered the straight portions of the curves in Figures 2.10 and 2.11, i.e., the data beyond the 
yield strain. The estimated $L_{\text {eff }}$ and the physical gauge length are given in Table 2.2 for the two strain rates. The corresponding estimated strain-versus-stress curves with respect to crosshead and actuator position measurements are shown in Figures 2.12 and 2.13, respectively. In addition, the scalar material properties estimated from the above-mentioned tensile test data can be found in Table 2.3.

Table 2. 2 Estimated effective gauge length and specimen nominal gauge length

\begin{tabular}{|c|c|c|c|}
\hline \multirow{2}{*}{ Strain rate } & \multicolumn{2}{|c|}{$L_{\text {eff }}$ estimate in mm (in.) } & \multirow{2}{*}{$\begin{array}{c}\text { Specimen nominal } \\
\text { gauge length in mm } \\
\text { (in.) }\end{array}$} \\
\cline { 2 - 3 } & $\begin{array}{c}\text { Based on crosshead } \\
\text { displacement }\end{array}$ & $\begin{array}{c}\text { Based on actuator } \\
\text { displacement }\end{array}$ & $14.25(0.561)$ \\
\hline $0.0001 / \mathrm{s}$ & $16.507(0.649)$ & $17.272(0.68)$ & $14.25(0.561)$ \\
\hline $0.001 / \mathrm{s}$ & $16.842(0.663)$ & $17.268(0.68)$ & \\
\hline
\end{tabular}

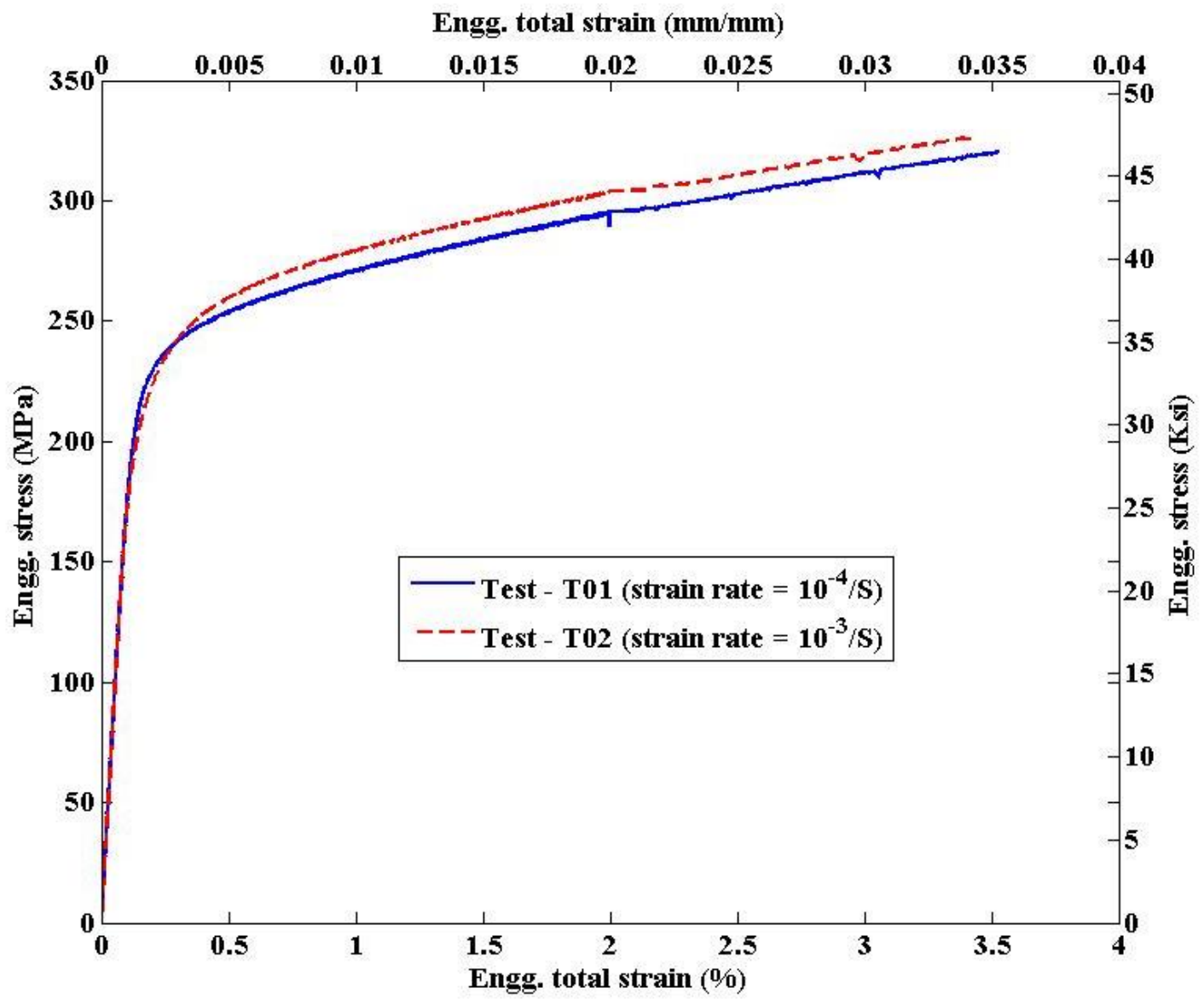

Figure 2.12 Strain-versus-stress curves estimated from crosshead displacement measurements 


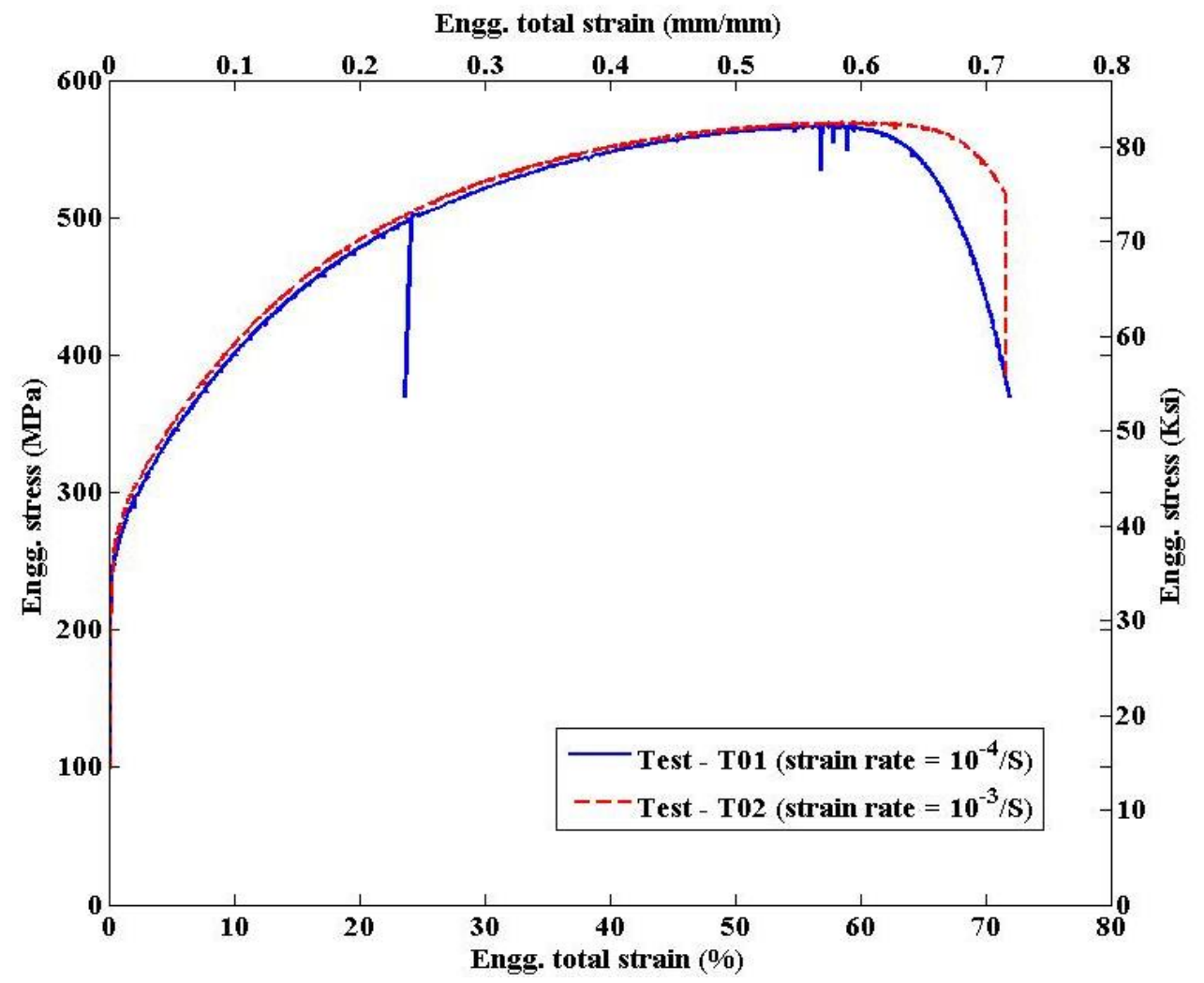

Figure 2.13 Strain-versus-stress curve estimated from actuator position measurements

Table 2.3 Estimated material properties of $316 \mathrm{SS}$ base metal at room temperature

\begin{tabular}{|c|c|c|c|c|c|c|}
\hline Test number & $\begin{array}{c}\text { Elastic } \\
\text { modulus in } \\
\text { GPa }(\mathrm{ksi})\end{array}$ & $\begin{array}{c}0.2 \% \text { yield } \\
\text { stress } \\
\text { in MPa }(\mathrm{ksi})\end{array}$ & $\begin{array}{c}\text { Ultimate } \\
\text { stress } \\
\text { in MPa }(\mathrm{ksi})\end{array}$ & $\begin{array}{c}\text { Fracture } \\
\text { stress in MPa } \\
(\mathrm{ksi})\end{array}$ & $\begin{array}{c}\text { Fracture } \\
\text { strain } \\
(\%)\end{array}$ & $\begin{array}{c}\text { Reduction in } \\
\text { gauge area } \\
(\%)\end{array}$ \\
\hline $\begin{array}{c}\text { T01 } \\
\text { (strain rate }=\end{array}$ & $\begin{array}{c}197.3 \\
0.0001 / \mathrm{s})\end{array}$ & $\begin{array}{c}245.1 \\
\text { (28615.9) }\end{array}$ & $\begin{array}{c}568.9 \\
(35.55)\end{array}$ & $\begin{array}{c}369.5 \\
(82.51)\end{array}$ & 71.88 & 84.4 \\
\hline $\begin{array}{c}\text { T02 } \\
(\text { strain rate }=\end{array}$ & $\begin{array}{c}(285.59) \\
0.001 / \mathrm{s})\end{array}$ & $\begin{array}{c}245.3 \\
(35.58)\end{array}$ & $\begin{array}{c}569.1 \\
(82.54)\end{array}$ & $\begin{array}{c}380.5 \\
(55.18)\end{array}$ & 71.57 & 83.1 \\
\hline
\end{tabular}

\subsection{Conclusion}

Room-temperature tensile tests of 316 SS base metal have been conducted under two strain rates: $0.0001 / \mathrm{s}$ and $0.001 / \mathrm{s}$. Based on these data, material properties and stress-strain curves were estimated. These test results are being or will be used in finite-element-based mechanistic modeling and for selection of test parameters for related fatigue testing in the LWRS program. 


\section{Mechanistic Modeling of Crack Initiation and Crack Propagation Using XFEM}

\subsection{Introduction}

Mechanistic modeling of environmental damage, such as stress corrosion cracking (SCC) and corrosion fatigue $(\mathrm{CF})$, requires crack initiation and/or propagation modeling. Finite element techniques can be used for this purpose. However, modeling crack propagation using the conventional finite element method (FEM) is highly cumbersome, particularly for moving crack tips, because it requires remeshing of the finite element domain after each crack propagation increment. In addition, the crack path must be known beforehand, as well as which remeshing has to be performed. However, in reality, the crack may follow an arbitrary path, and efficient crack propagation modeling requires the crack path to be solution dependent or automatic. In conventional FEM, at each time interval during which the crack grows, the element boundary has to be aligned along the crack path, which may not be the case in practice. Also, conventional FEM often fails to converge while modeling discontinuities, such as cracks. All of the abovementioned limitations restricted the use of conventional FEM for modeling the moving crack tip. However, with the recent advancement of the extended finite element method (XFEM), modeling moving cracks has become possible. The development of XFEM was first linked to the work of Babuska, et al. [3] and Melenk and Babuska [4]. They proposed the partition of unity method (PUM), which allows the use of local enrichment functions to model cracks. This helps avoid singularity problems associated with discontinuities in conventional FEM. Also, the development of the level set method (LSM) [5,6] has made it easier to model cracks, particularly for modeling moving interfaces or shapes, such as cracks. The LSM has made it possible to perform numerical computations involving curves and surfaces on a fixed Cartesian grid without having to parameterize the bulk material or object. Belytschko and Black [7] first extended the concept of PUM and LSM to conventional FEM for solving linear elastic fracture mechanics problems. The resulting method is popularly known as the extended finite element method or XFEM. The XFEM method was further improved by many other researchers [8-16] and has recently been implemented in commercially available software, such as ABAQUS [17]. In the present work, the use of XFEM through ABAQUS is evaluated by modeling crack initiation and propagation in steam generator tubes. Currently, the model does not consider the environmental effects of $\mathrm{SCC} / \mathrm{CF}$, only the transient crack initiation and propagation at room temperature. However, in the future SCC/CS will be modeled using XFEM as one of the computational tools. The current results have been validated against the experimental results available under ANL's steam regenerator tube integrity program sponsored by NRC [18]. The details of the model and results are discussed in the following subsections. 


\subsection{Theoretical background}

\subsubsection{Extended finite element method: Generic theoretical background}

In the generic XFEM framework [7-15], the displacement field in a finite element crack domain can be expressed as

$$
\begin{aligned}
u & =\sum_{i}^{N} N_{i}(x) q_{i}+\text { enriched function } \\
& =\sum_{i=1}^{N} N_{i}(x) q_{i}+\sum_{i=1}^{N} N_{i}(x) H(x) a_{i}+\sum_{i=1}^{N} N_{i}(x) \sum_{\alpha=1}^{4} F_{\alpha} b_{i}^{\alpha} \\
& =\sum_{i=1}^{N} N_{i}(x)\left[q_{i}+H(x) a_{i}+\sum_{\alpha=1}^{4} F_{\alpha} b_{i}^{\alpha}\right]
\end{aligned}
$$

where $N_{i}(x)$ and $q_{i}$ are, respectively, the usual nodal shape functions and nodal degree-offreedom (DOF) vector used in conventional FEM and associated with the continuous part of the finite element model; $H(x)$ and $a_{i}$ are, respectively, the Heaviside function and nodal-enriched DOFs associated with the cracked geometry; and $F_{\alpha}$ and $b_{i}^{\alpha}$ are, respectively, the additional asymptotic crack tip functions and the associated enriched-nodal DOFs. The Heaviside function $H(x)$ can be given as

$$
H(x)= \begin{cases}+1 & x \text { above the crack surface } \\ -1 & x \text { below the crack surface }\end{cases}
$$

The asymptotic crack tip functions $F_{\alpha}$ can be given as

$$
F_{\alpha}(x)=\left\{\sqrt{r} \sin \left(\frac{\theta}{2}\right), \quad \sqrt{r} \cos \left(\frac{\theta}{2}\right), \quad \sqrt{r} \sin (\theta) \sin \left(\frac{\theta}{2}\right), \quad \sqrt{r} \sin (\theta) \cos \left(\frac{\theta}{2}\right)\right\}
$$

where $(r, \theta)$ is the polar coordinate system with its origin at the crack tip. The finite element global equilibrium equation associated with the displacement field in Eq. (3.1) can be given as

$$
\left[\begin{array}{lll}
\mathbf{K}_{\mathrm{qq}} & \mathbf{K}_{\mathrm{qa}} & \mathbf{K}_{\mathrm{qb}} \\
\mathbf{K}_{\mathrm{aq}} & \mathbf{K}_{\mathrm{aa}} & \mathbf{K}_{\mathrm{ab}} \\
\mathbf{K}_{\mathrm{bq}} & \mathbf{K}_{\mathrm{ba}} & \mathbf{K}_{\mathrm{bb}}
\end{array}\right]\left\{\begin{array}{l}
\mathbf{q} \\
\mathbf{a} \\
\mathbf{b}
\end{array}\right\}=\left\{\begin{array}{c}
\mathbf{f}_{\mathbf{q}} \\
\mathbf{f}_{\mathrm{a}} \\
\mathbf{f}_{\mathrm{b}}
\end{array}\right\}
$$

The element stiffness matrix associated with the global equilibrium in Eq. (3.4) can be given as 


$$
\left[\begin{array}{lll}
\mathbf{K}_{q q}^{e} & \mathbf{K}_{q a}^{e} & \mathbf{K}_{q b}^{e} \\
\mathbf{K}_{a q}^{e} & \mathbf{K}_{a a}^{e} & \mathbf{K}_{a b}^{e} \\
\mathbf{K}_{b q}^{e} & \mathbf{K}_{b a}^{e} & \mathbf{K}_{b b}^{e}
\end{array}\right]=\int \operatorname{A}_{e}\left[\begin{array}{lll}
\mathbf{B}_{\mathbf{q}}^{\mathbf{T}} \mathbf{D} \mathbf{B}_{\mathbf{q}} & \mathbf{B}_{\mathbf{q}}^{\mathbf{T}} \mathbf{D} \mathbf{B}_{\mathbf{a}} & \mathbf{B}_{\mathbf{q}}^{\mathbf{T}} \mathbf{D} \mathbf{B}_{\mathbf{b}} \\
\mathbf{B}_{\mathbf{a}}^{\mathbf{T}} \mathbf{D} \mathbf{B}_{\mathbf{q}} & \mathbf{B}_{\mathbf{a}}^{\mathbf{T}} \mathbf{D} \mathbf{B}_{\mathbf{a}} & \mathbf{B}_{\mathbf{a}}^{\mathbf{T}} \mathbf{D} \mathbf{B}_{\mathbf{b}} \\
\mathbf{B}_{\mathbf{b}}^{\mathbf{T}} \mathbf{D} \mathbf{B}_{\mathbf{q}} & \mathbf{B}_{\mathbf{b}}^{\mathbf{T}} \mathbf{D} \mathbf{B}_{\mathbf{a}} & \mathbf{B}_{\mathbf{a}}^{\mathrm{T}} \mathbf{D} \mathbf{B}_{\mathbf{a}}
\end{array}\right] d A_{e}
$$

In Eq. (3.5), $\mathbf{D}$ is the material property matrix, and $\mathbf{B}$ stands for the respective straindisplacement matrix associated with the conventional finite element nodal DOFs (subscript $\mathbf{q}$ ), crack domain enriched-nodal DOFs (subscript a), and crack tip-enriched nodal DOFs (subscript b).

\subsubsection{XFEM modeling through ABAQUS}

In the present work, commercially available ABAQUS based extended finite element technique is used to model the initiation and propagation of moving cracks in steam generator tubes. To note that for simplicity the current version of ABAQUS does not allow considering the displacement field associated with the asymptotic crack tip functions given in Eq. (3.1), particularly for modeling moving cracks. The total displacement field considered for modeling a moving crack in the present work can then be as follows:

$$
\begin{aligned}
u & =\sum_{i}^{N} N_{i}(x) q_{i}+\text { enriched function } \\
& =\sum_{i=1}^{N} N_{i}(x) q_{i}+\sum_{i=1}^{N} N_{i}(x) H(x) a_{i}=\sum_{i=1}^{N} N_{i}(x)\left[q_{i}+H(x) a_{i}\right]
\end{aligned}
$$

In addition to the techniques common to conventional FEM, the XFEM procedure in ABAQUS has additional techniques, such as phantom node modeling, level set methods, and cohesive zone modeling. A brief discussion of these techniques is given below. The details of these techniques can be found in the ABAQUS user manual [17] and elsewhere in the literature [5-16] related to these topics.

\section{Phantom node modeling approach}

In the phantom node approach, additional nodes are created surrounding the crack. These nodes remain even after the crack has passed through that element. These nodes are introduced to represent the discontinuity associated with the cracked elements. These phantom nodes are associated with the Heaviside function $H(x)$ in Eq. (3.6). The location of the phantom nodes with respect to real nodes and the cracked element is schematically shown in Fig. 3.1. Phantom nodes are automatically created in the crack tip element of the uncracked mesh. These nodes are superimposed on the real nodes of the element, and when the element is intact these phantom nodes are fully constrained to the real nodes. When the crack passes through the element, the element gets separated into two superimposed elements, consisting of a combination of real nodes and phantom nodes, as shown in Fig. 3.1b. In the new elements, the cracked surfaces are separated according to traction separation techniques, which are described in the following 
subsection. Unlike the uncracked finite elements, the time-dependent stiffness matrix of the new cracked element is computed by integrating over the area from the side of the real nodes up to the crack surface only. For example, the stiffness matrix of the cracked element shown in Figure 3.1 can be expressed as below:

$$
\int_{A_{e}}\left(B^{T} D B\right) d A_{e}=\int_{A_{t}}\left(B^{T} D B\right) d A_{t}+\int_{A_{b}}\left(B^{T} D B\right) d A_{b}
$$

where $A_{t}$ and $A_{b}$ are the real area of the top and bottom portion of the cracked element, respectively.

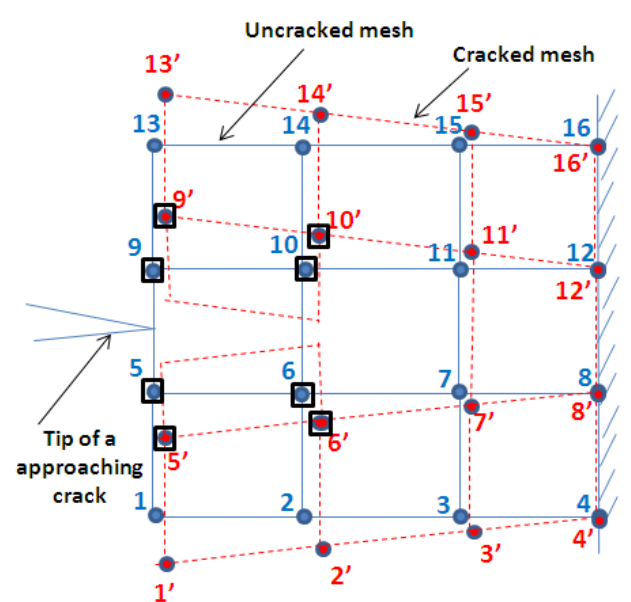

a)

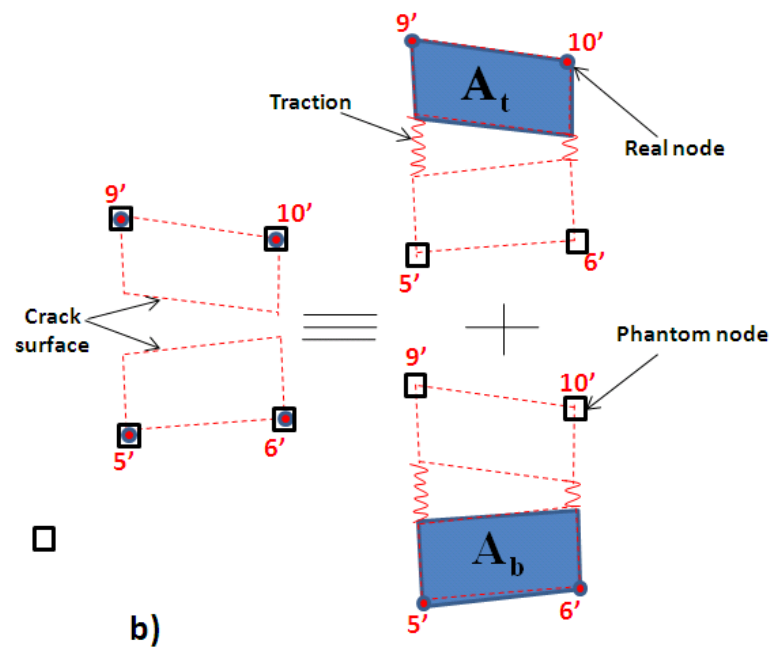

b)

Figure 3.1 Schematic of (a) cracked and uncracked mesh showing real and phantom nodes and (b) cracked element as sum of two virtual or phantom elements

\section{Level set method}

In the XFEM framework it is essential to automatically track the crack surface and crack front. This tracking is made possible by the level set representation, in which the crack plane surface and crack tip surface are represented by two level set functions or fields. Figure 3.2 schematically shows the level set fields for the crack plane surface and crack tip surface represented by $\Phi=0$ and $\psi=0$, respectively [15]. These surfaces are assumed orthogonal, such that $\nabla \Phi . \nabla \Psi=0$. The values of these fields are time or solution dependent. These functions are computed on a narrow band of grid points surrounding the crack surface and tip. These field values can be used not only to obtain the geometric information regarding the location of the crack but also the local coordinate system that can be used to generate the enrichment function $H(x)$ in Eq. (3.6). The LSM does not require explicit representations of the crack boundary/interface because they are defined entirely by the solution-dependent surfaces, $\Phi=0$ and $\psi=0$. 


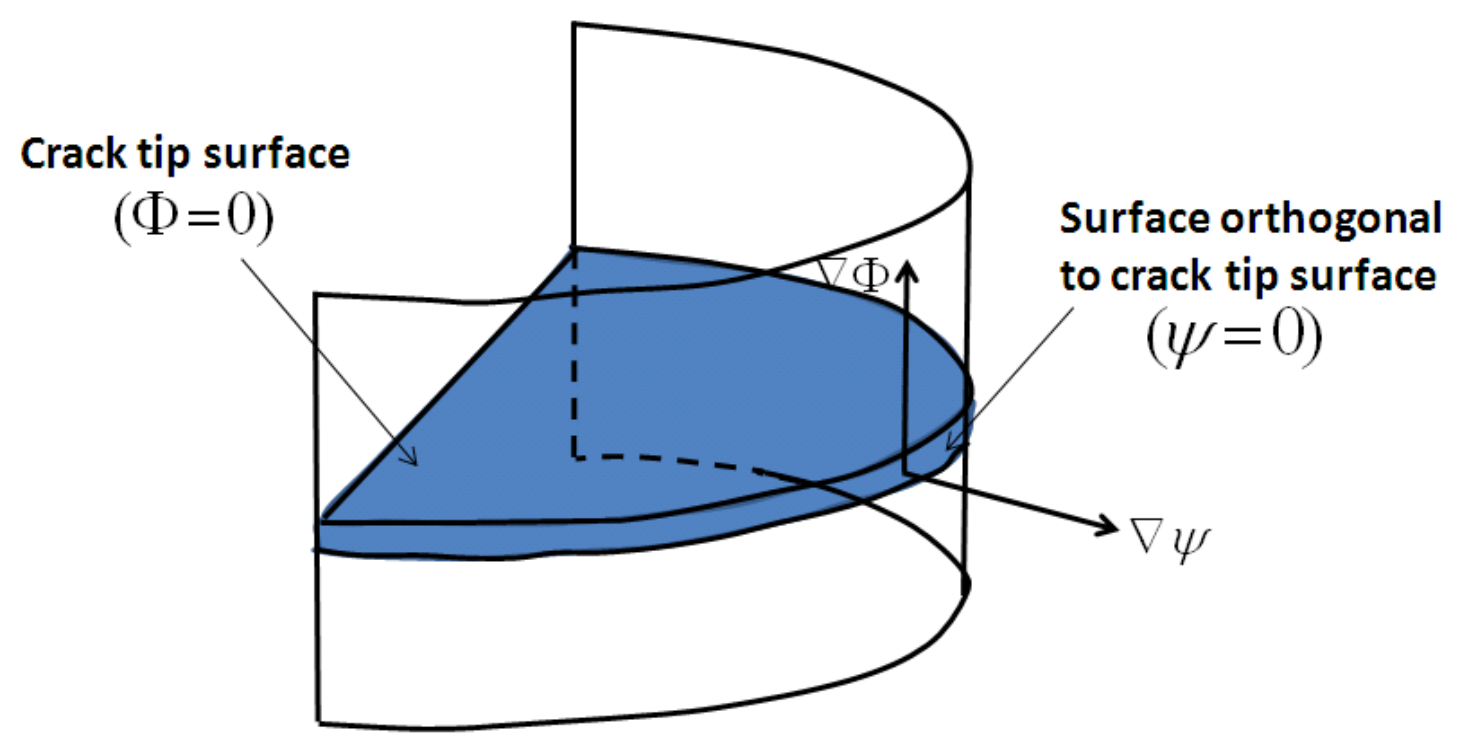

Figure 3.2 Schematic showing the orthogonal level set fields that describe the crack tip

\section{Crack initiation criteria}

A crack, to be initiated in any element, has to satisfy certain criteria. Different initiation criteria can be defined in terms of solution-dependent stress, strain, etc., and respective critical values. In the present work, the maximum principal stress criterion is used for the initiation of the crack. The maximum principal stress initiation criterion is given below:

$$
f=\frac{\left\langle\sigma_{\max }^{p}\right\rangle}{\sigma_{c r}^{p}}=\left\{\begin{array}{l}
\geq 1+f_{\text {tol }} \quad \text { crack will initiate } \\
<1+f_{\text {tol }} \quad \text { crack will not initiate }
\end{array}\right.
$$

where $\sigma_{\max }^{p}$ is the solution-dependent maximum principal stress, and $\sigma_{c r}^{p}$ is the critical principal stress that has to be provided as an input material property. In Eq. (3.8), the symbol \langle\rangle represents Macaulay brackets with $\left\langle\sigma_{\max }^{p}\right\rangle=0$ if $\sigma_{\max }^{p}<0$, i.e., when the maximum principal stress is purely compressive.

\section{Crack evolution through traction separation criteria}

Crack evolution criteria describe the rate at which traction is applied to the cracked surface of the cracked element following initiation. The traction in a cracked element is shown schematically in Fig. 3.1b. The three-dimensional traction in a cracked element can be found by using the following expression: 


$$
t=\left\{\begin{array}{l}
t_{n} \\
t_{s} \\
t_{t}
\end{array}\right\}=\left[\begin{array}{ccc}
K_{n n} & 0 & 0 \\
0 & K_{s s} & 0 \\
0 & 0 & K_{t t}
\end{array}\right]\left\{\begin{array}{l}
\delta_{n} \\
\delta_{s} \\
\delta_{t}
\end{array}\right\}
$$

where $K_{i i, i=n, s, t}$ are calculated based on the elastic properties of the cracked element; $t_{n}, t_{s}$, and $t_{t}$ are the traction along normal, first shear, and second shear directions; and $\delta_{n}, \delta_{s}$, and $\delta_{t}$ are the respective separation displacements. The separation displacements can be calculated using the traction separation curve $[19,20]$, shown in Fig. 3.3.

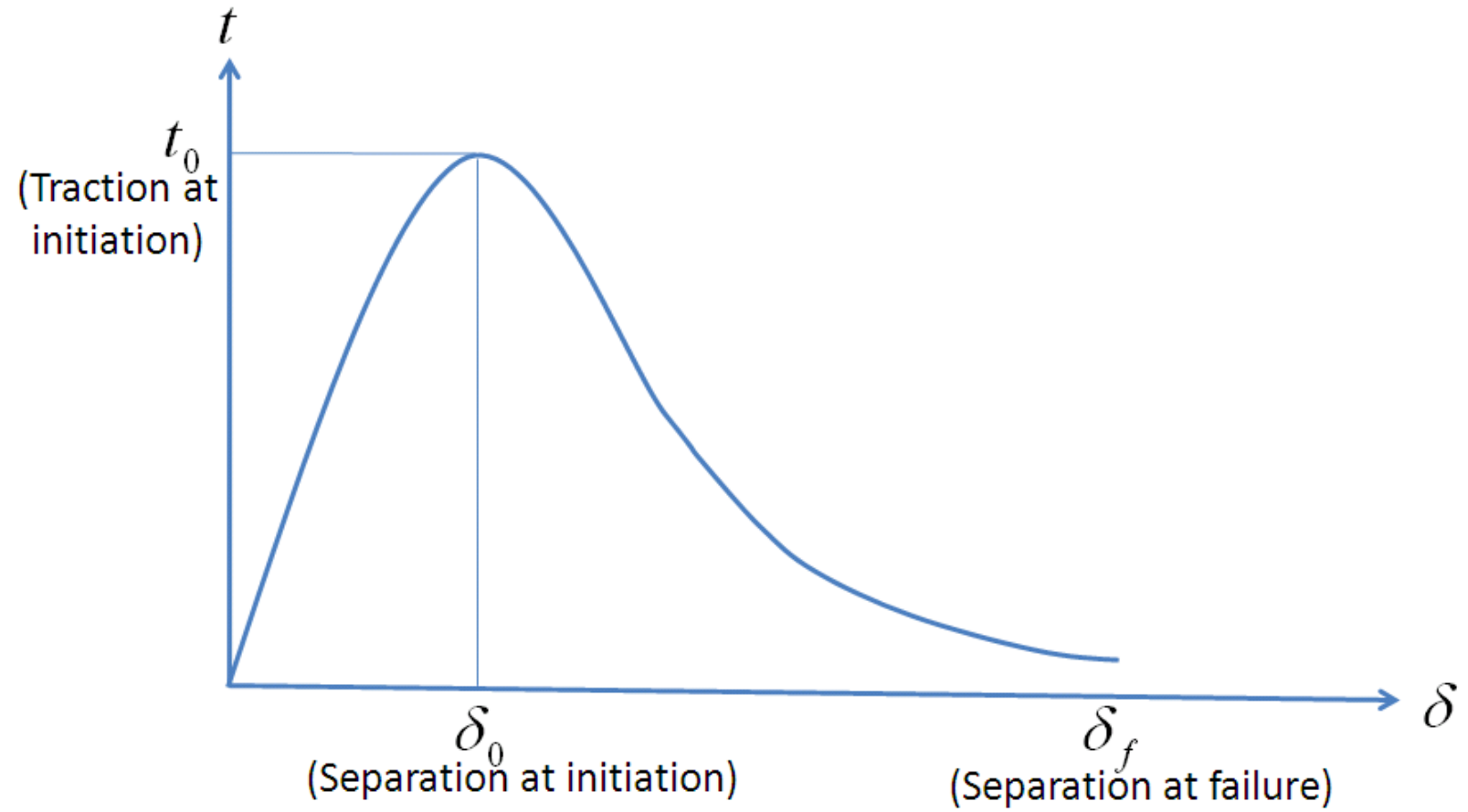

Figure 3.3 Schematic of traction separation curve

The area under the curve in Figure 3.3 can be assumed to represent the fracture energy. For simplicity, assuming linear traction separation behavior, and hence a linear traction separation curve, the separation displacement $\delta$ can be calculated from

$$
G_{c r}=\frac{1}{2} t_{0} \delta_{f}
$$

where $G_{c r}$ is the critical fracture energy or fracture toughness, and $t_{0}$ is the solution-dependent traction at crack initiation and can be related to the crack initiation principal stress $\sigma_{0} \geq \sigma_{c r}^{p}$, where $\sigma_{c r}^{p}$ is the critical principal stress given by Eq. (3.8). 


\subsection{Results and analysis}

The above XFEM technique was used to model crack initiation and propagation in steam generator (SG) tubes under simulated severe accident conditions. The results are compared with the experimental data obtained through the NRC-sponsored SG tube integrity experiments conducted at ANL. Multiple Alloy 600 SG tubes were tested under different pressure conditions, and the details of these tests can be found in NUREG/CR-6804 [18]. In the present report, only a few prototypical cases are considered to verify the capability of the XFEM modeling techniques. The details of the model and results are discussed below.

\subsubsection{SG tube model with single initial crack}

In the first case, SG tube models were developed with a single preexisting part-through-wall axial crack from the outer diameter (OD) surface. The tubes had an OD of $22.2 \mathrm{~mm}$ (7/8 in.), and a thickness of $1.27 \mathrm{~mm}$ and were made from Alloy 600 material. The material properties considered for the present FEM are given in Table 3.1, and the stress-strain curve is shown in Figure 3.4. Three-dimensional brick elements were used to model the tube. The initial crack was modeled as a shell or planar geometry and assembled to the tube geometry. A typical FEM model of an SG tube is shown in Figure 3.5. The model also included a part-through-wall OD axial crack with length of $6.35 \mathrm{~mm}$ and a ratio for the crack depth to tube wall thickness $(\mathrm{a} / \mathrm{h})$ of $75 \%$. In the FEM model the geometric and force boundary conditions are applied such that it can equivalently represent the experimental boundary conditions. In the NRC-sponsored SG tube integrity experiments, one end of the SG tube was fixed to the compressed air flow path, whereas the other end was plugged to help build up the pressure inside the tube. As in the experiment conditions, the FEM model inner surface was subjected to an increasing pressure. In addition, an equivalent longitudinal pressure applied to the end plug was used to simulate the far-field biaxial stress field. Crack initiation and propagation were simulated for an increasing applied internal pressure. Note that the propagation of the initial crack does not occur immediately after the pressurization starts. The crack may start growing only after a critical pressure is reached.

Table 3.1 Room-temperature material properties for Alloy 600

\begin{tabular}{|c|c|}
\hline Elastic modulus $(\mathrm{GPa})$ & 200 \\
\hline Poisson's ratio & 0.3 \\
\hline Yield strength $\sigma_{y}(\mathrm{MPa})$ & 296 \\
\hline Ultimate strength $\sigma_{u}(\mathrm{MPa})$ & 684 \\
\hline Critical principal stress in Eq. (3.8) \\
$\sigma_{c r}^{p}=0.5\left(\sigma_{y}+\sigma_{u}\right)$
\end{tabular}




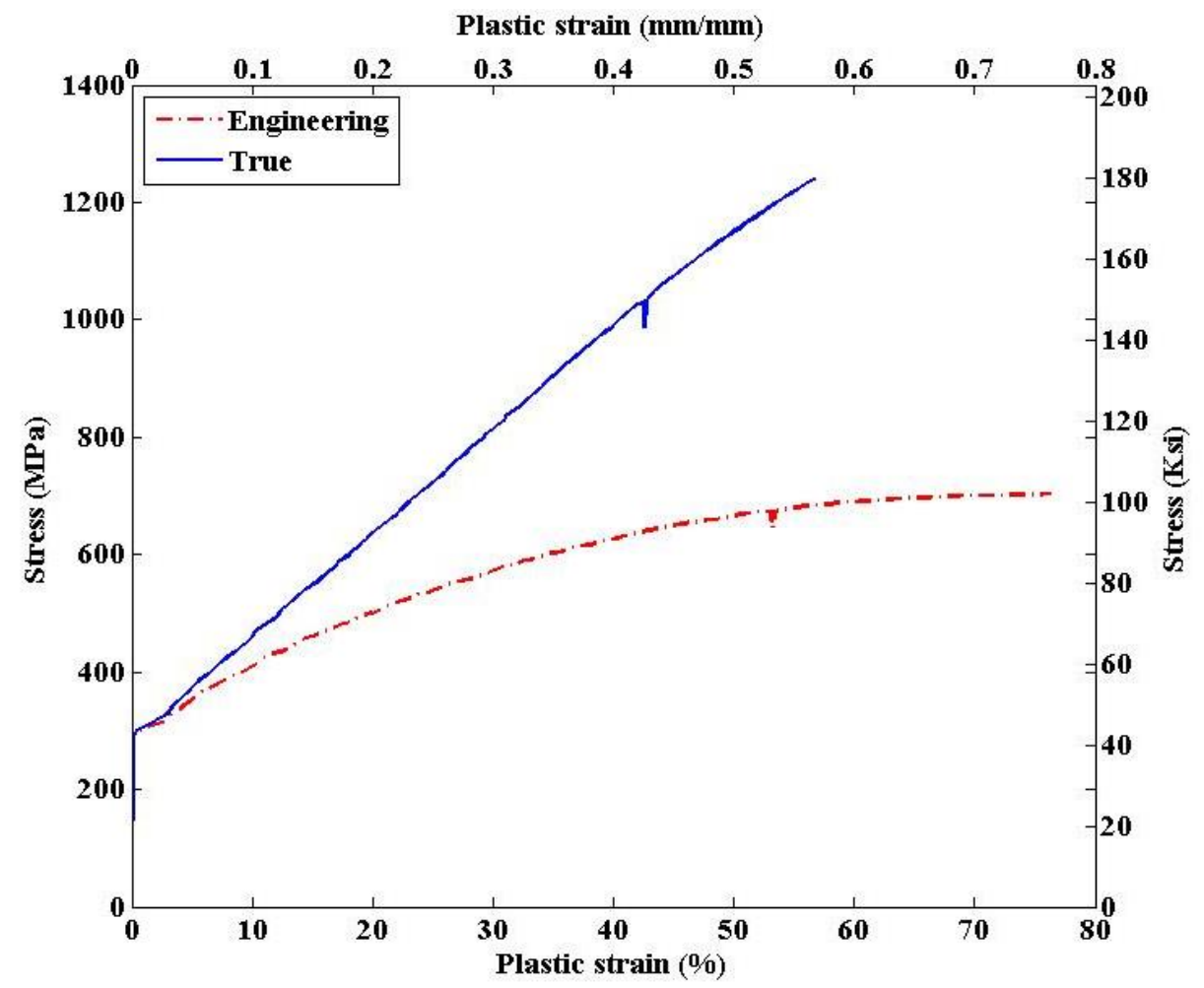

Figure 3.4 Room-temperature stress-strain curves for Alloy 600

a)

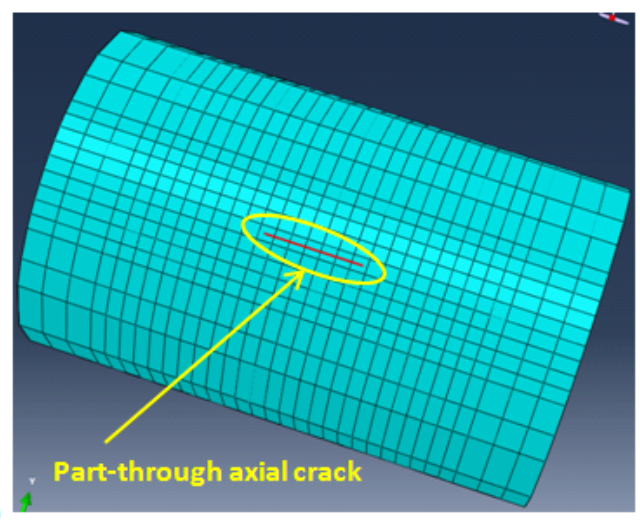

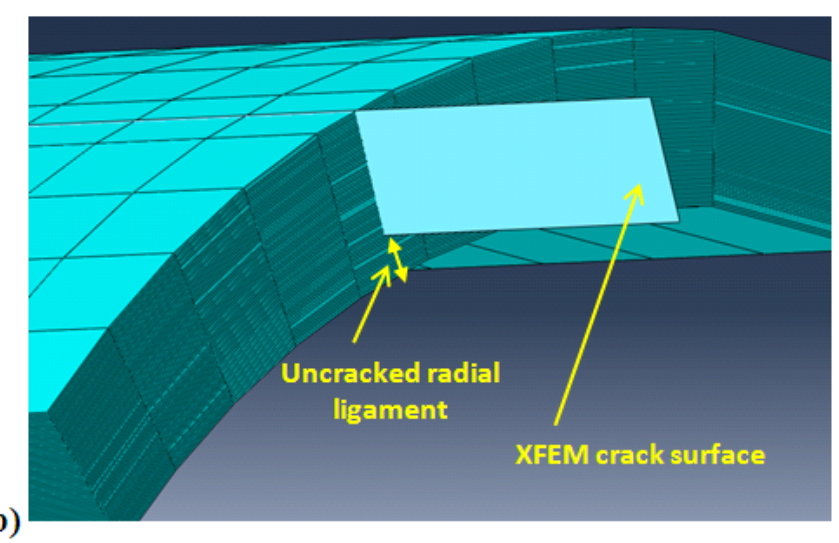

b)

Figure 3.5 Typical FEM model of a 22.2-mm (7/8-in.) OD tube with an initial crack length of $6.35 \mathrm{~mm}$ and crack depth to wall thickness ratio of 75\%: (a) OD surface and (b) cut section of the cross section

In real nuclear plants, SG tubes containing preexisting SCC cracks may start to grow due to a pressure transient when the internal pressure reaches a critical value. Such case may occur during a design-basis accident. In the XFEM model, this critical pressure can be estimated when the solution-dependent maximum principal stress equals or exceeds the limiting critical principal stress $\sigma_{c r}^{p}$, as given by Eq. (3.8). In all the XFEM models discussed in this work, $\sigma_{c r}^{p}$ is assumed 
to be represented mathematically as $\sigma_{c r}^{p}=0.5\left(\sigma_{y}+\sigma_{u}\right)$, which is approximately the flow stress of the material. The predicted ligament rupture and final burst pressures based on this assumption match the corresponding experimental values reasonably well. Note that in the experiment, the crack after initiation did not arrest but continued to propagate unstably until full ligament rupture (but before burst). The details of the findings are discussed further below.

For the FEM model shown in Fig. 3.5, the maximum principal stress distribution at an applied pressure of $24.66 \mathrm{MPa}$ is shown in Fig. 3.6. The simulation results indicate that the crack starts and begins to propagate along the radial or wall thickness direction at this pressure. They also indicate that the maximum principal stress at the crack tip element exceeds the limiting principal stress $\left(\sigma_{c r}^{p}\right)$ of $490 \mathrm{MPa}$ (Table 3.1). After initiation, the crack grows further in the radial direction (along the thickness) and ruptures the last ligament in the inner diameter (ID) surface. The corresponding applied pressure is referred to here as "ligament rupture pressure." After the ID ligament ruptures, the crack grows further in the axial direction unstably with increasing pressure until the FEM calculation fails to converge because of issues associated with large plastic deformation. The corresponding applied internal pressure is referred to as the "burst pressure." For the FEM model shown in Fig. 3.5, the estimated ID ligament rupture and burst pressure were found to be $37.73 \mathrm{MPa}$ and $40.01 \mathrm{MPa}$, respectively. The corresponding experimental values were reported as 36.5 and $41.2 \mathrm{MPa}$, respectively, showing a good correlation between the XFEM model and experimental results. Figures $3.7 \mathrm{a}$ and $3.7 \mathrm{~b}$ show the corresponding OD surface shape at the ligament rupture pressure and burst pressure, respectively. The experimental specimen after bursting, shown in Fig. 3.8, has a remarkably similar geometry to the FEM-predicted shape (Figure 3.7b). Figure 3.9 shows the timedependent (or with respect to applied pressure) crack opening displacement (COD) at the OD and ID surface. It shows that, although the OD COD is larger than the ID COD, both increase unstably after the ID ligament rupture. Figure 3.10 shows the estimated equivalent plastic strain with respect to applied pressure at a radial crack-tip element (in front of the initial crack) and at a central ID ligament element. Figures 3.9 and 3.10 both show that the COD and the maximum equivalent plastic strain behave in a similar manner with increasing pressure. In addition to the above-mentioned model, additional tube models were developed with different initial crack lengths and crack depth to wall thickness ratios $(\mathrm{a} / \mathrm{h})$. In a parametric study, some of these results are depicted in Figures 3.11 and 12. For example, Figure 3.11 shows the radial crack initiation pressure and ID ligament rupture pressure as functions of $\mathrm{a} / \mathrm{h}$. As $\mathrm{a} / \mathrm{h}$ increases, the corresponding radial crack initiation and ID ligament rupture pressures decrease non-linearly. Similar trends can also be seen with increasing initial crack length, as shown in Figure 3.12. 


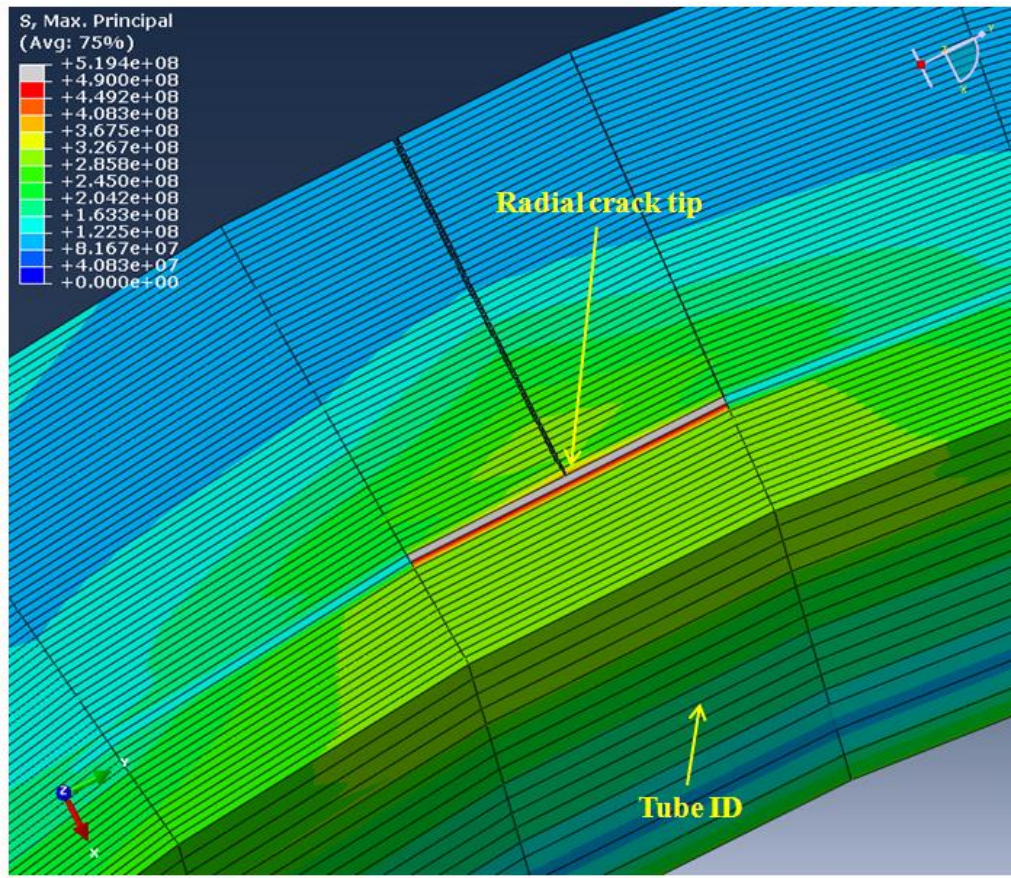

Figure 3.6 Maximum principal stress distribution upon exceeding the critical principal stress $\sigma_{c r}^{p}$ just before the crack initiation or cracking of the crack-tip element in front of initial crack in radial direction

a)

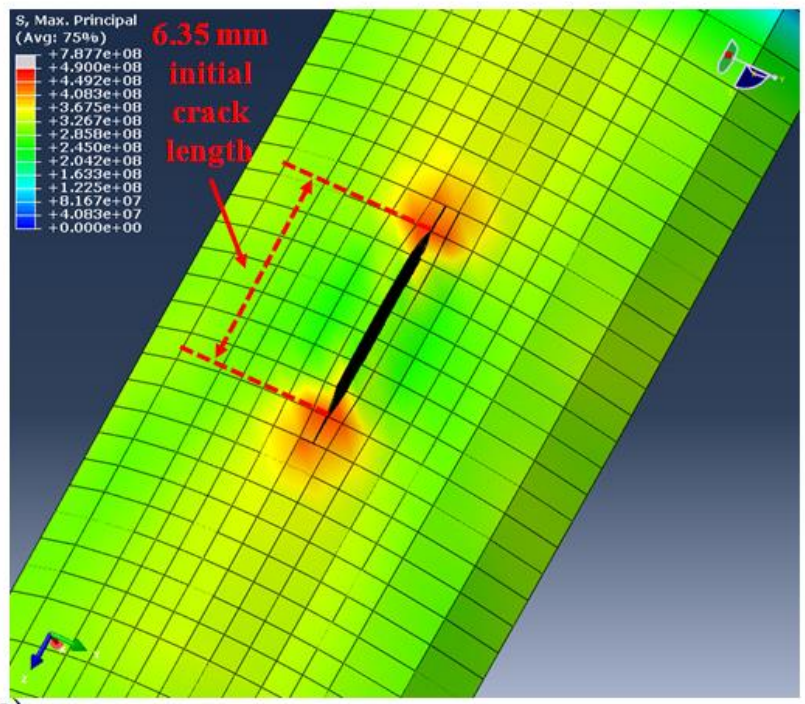

b)

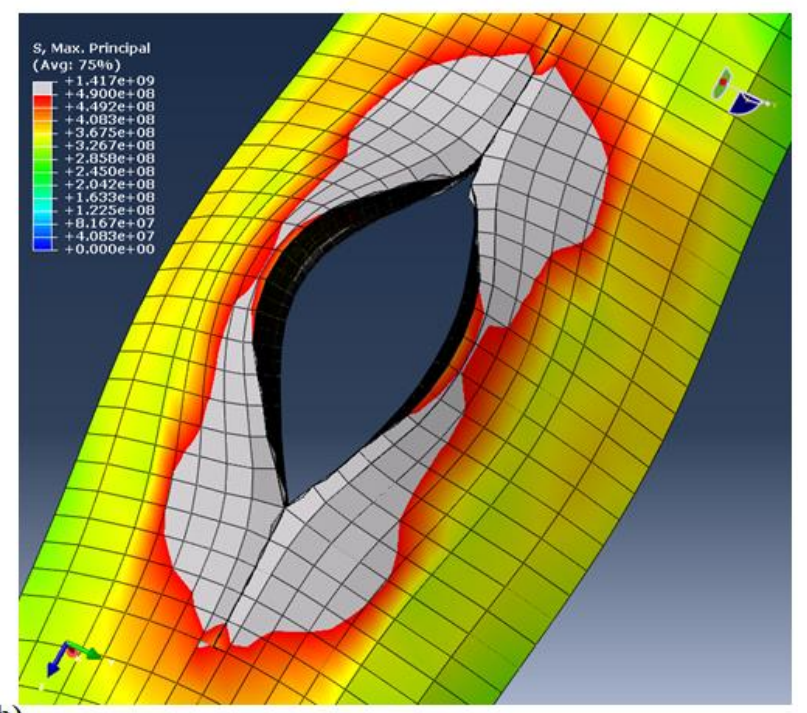

Figure 3.7 Shape of the OD surface and maximum principal stress distribution for the 22.2-mm OD tube at (a) ID ligament rupture pressure (37.5 MPa) and (b) final burst pressure (40.01 $\mathrm{MPa}$ ) 

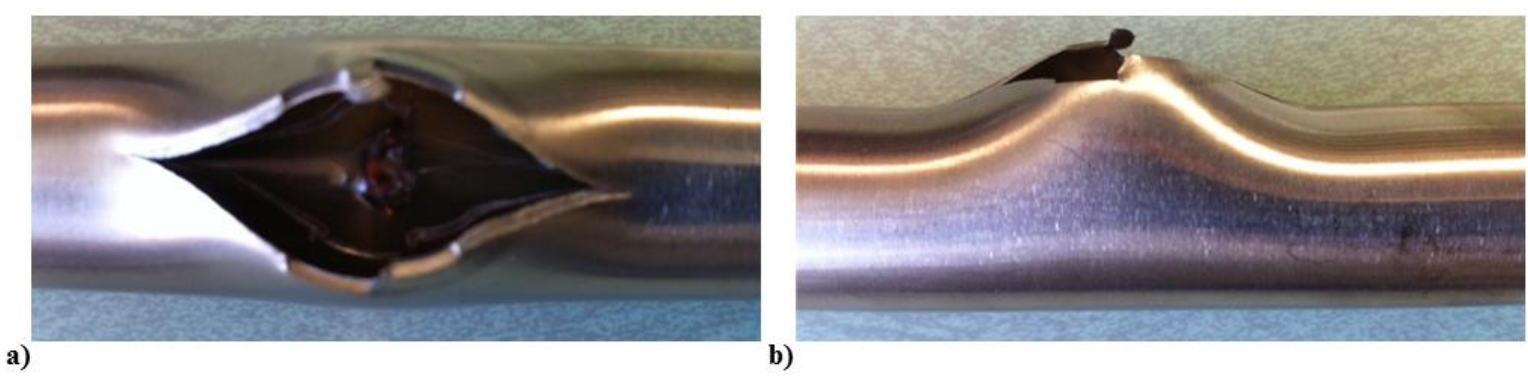

b)

Figure 3. 8 After burst shape of a typical 22.2-mm diameter tube with $6.35 \mathrm{~mm}$ initial notch: (a) top view and (b) side view

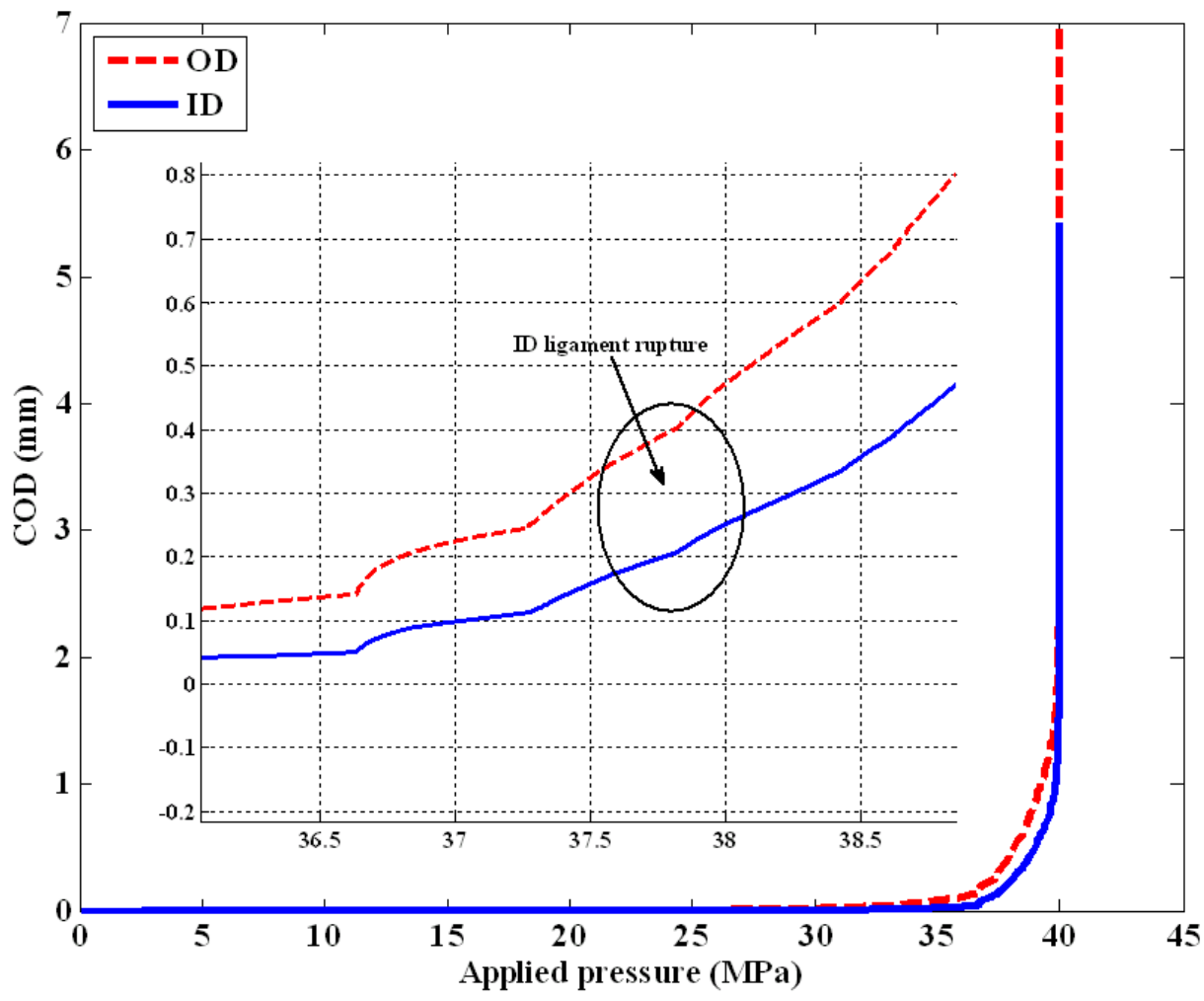

Figure 3. 9 Estimated COD with respect to applied pressure at the OD and ID surface of the 22.2-mm OD tube 


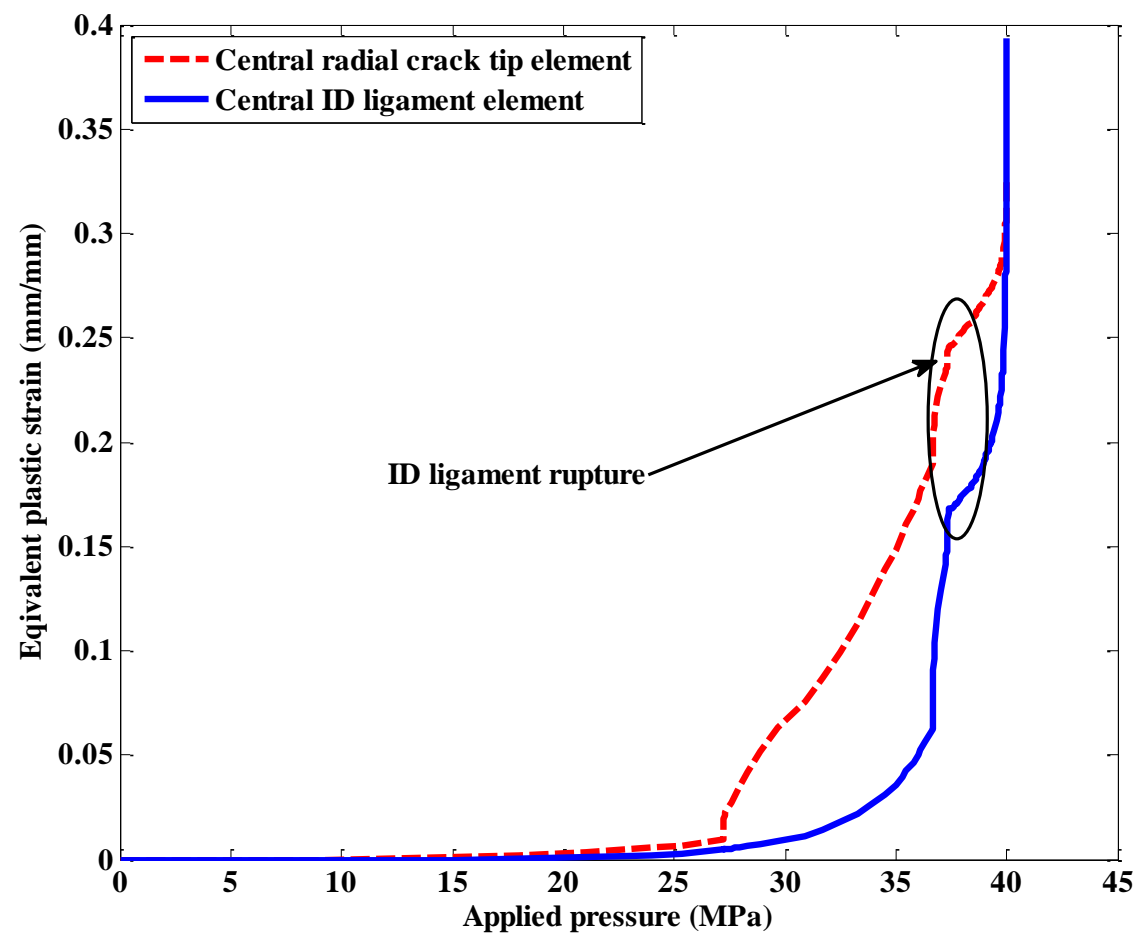

Figure 3. 10 Estimated equivalent plastic strain with respect to applied pressure at radial crack-tip element (in front of the initial crack) and central ID ligament element of the 22.2-mm OD tube

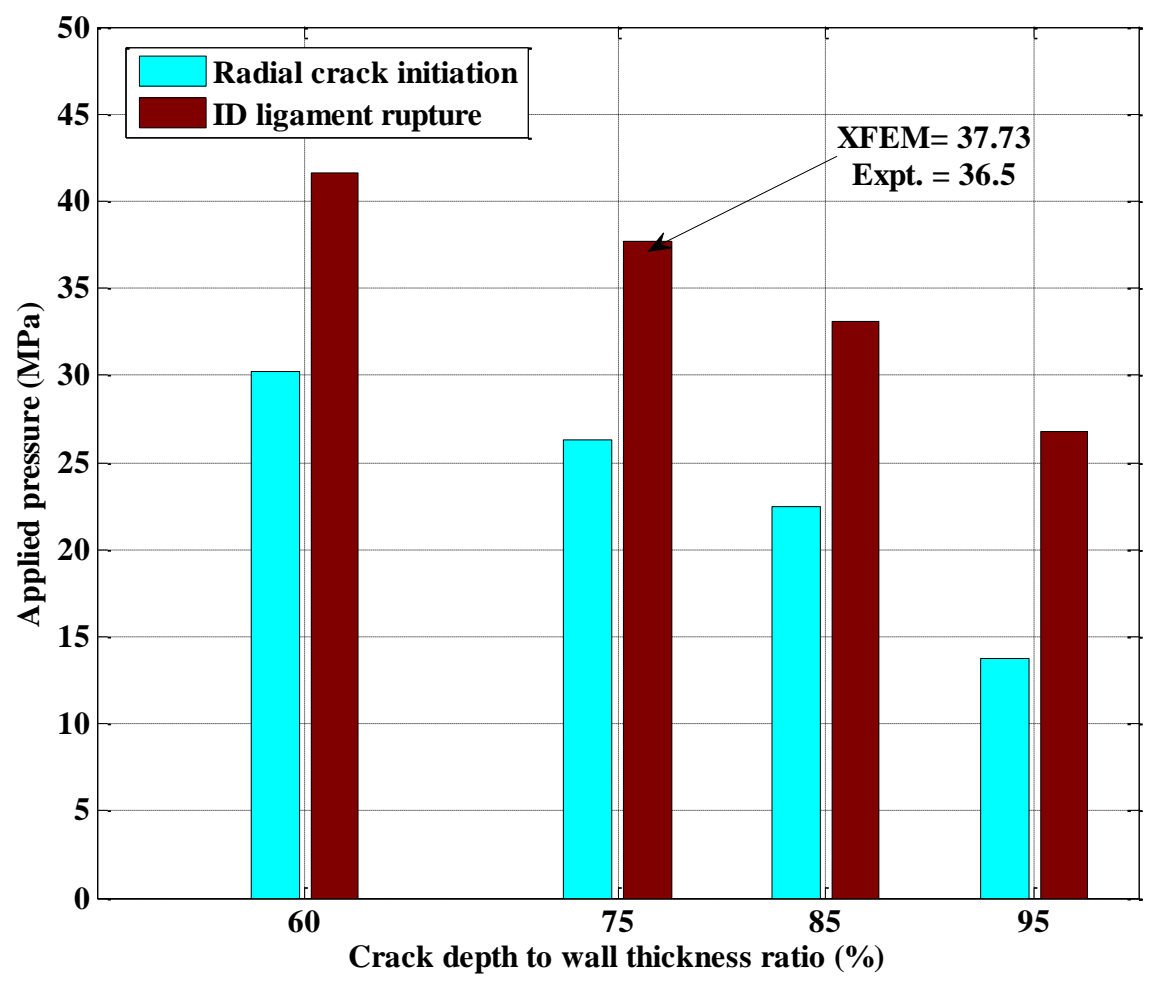

Figure 3. 11 Radial crack initiation pressure and ID ligament rupture pressure with respect to different ratios of initial crack depth to wall thickness 


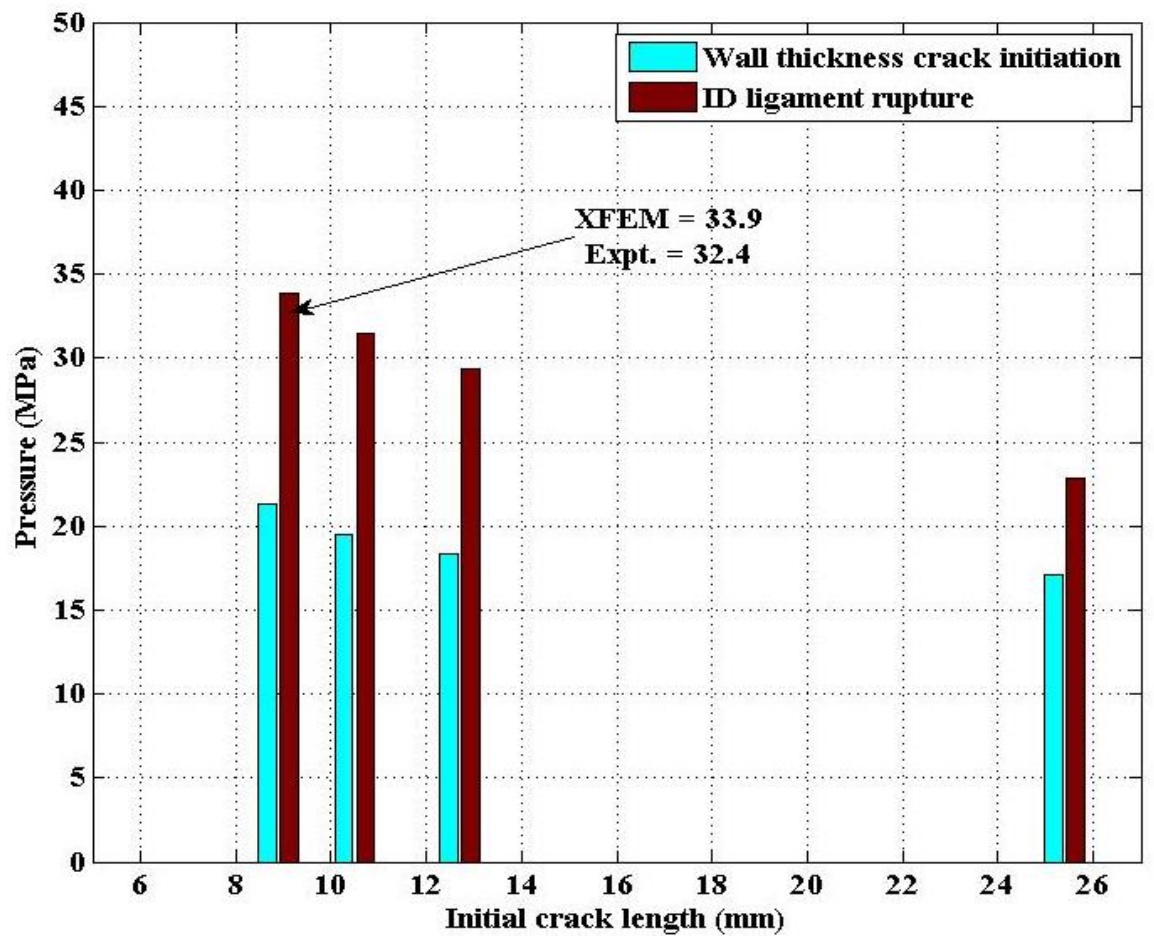

Figure 3.12 Radial or wall thickness crack initiation pressure and ID ligament rupture pressure with respect to different initial crack length

\subsubsection{SG tube model with two initial cracks for crack coalescence simulation}

In the second case, Alloy 600 SG tubes were modeled with two initial cracks to simulate crack coalescence. For this purpose, a 22.2-mm (7/8-in.) OD tube with different initial crack configurations was modeled. For example, Figure 3.13 shows the FEM model of the tube with two $72 \%$ part-through OD axial cracks, each with a length equal to $6.2 \mathrm{~mm}$. The two cracks are separated by an uncracked axial ligament of length $0.25 \mathrm{~mm}$. Figure 3.13 also shows an uncracked ligament of length $0.36 \mathrm{~mm}$ in the radial direction. Due to continuous pressurization, a sequence of events would occur that can easily be modeled through a single XFEM simulation. This model involves several consecutive events: the axial crack initiates at the crack-tip elements in the axial ligament; then, the uncracked axial ligament is completely ruptured, creating a single partial through-wall crack; then, the radial ligament crack initiate, propagate and completely ruptures, creating a single 100\% through-wall crack; then, the tube ruptures unstably. The predicted applied internal pressure corresponding to some of the above-mentioned events can be found in Table 3.2. For example, the tube in case 1 has an initial crack length of $12.7 \mathrm{~mm}(2 \mathrm{c}+$ b), $b=0.25 \mathrm{~mm}$, and $\mathrm{a} / \mathrm{h}$ ratio of $72 \%$; after pressurization the model predicts that the axial ligament crack initiates at applied internal pressure of $15.86 \mathrm{MPa}$, the corresponding uncracked axial ligament of length $b=0.25 \mathrm{~mm}$ completely ruptures at $16.81 \mathrm{MPa}$, and the uncracked radial ligament completely ruptures at $30.97 \mathrm{MPa}$. The latter is well correlated with the experimentally measured radial ligament rupture pressure of $33.8 \mathrm{MPa}$. The FEM program stopped at 31.22 MPa possibly due to a convergence problem associated with large accumulated plastic strain and 
unstable crack growth. The shapes of the OD surface at ID ligament rupture and final burst can be seen from Figures 3.14a and 3.14b, respectively. The corresponding variation in COD at OD and ID with respect to the applied pressure can be seen from Figure 3.15. As evident from the figures, after the ID ligament rupture, the COD grows unstably. Similar trends can also be observed from Figure 3.16, showing equivalent plastic strain at two OD and ID elements with respect to applied pressure. Figure 3.17 shows the equivalent plastic strain distribution near the ID crack region after the ID ligament ruptures at $30.97 \mathrm{MPa}$ applied pressure. This figure indicates substantial plastic strains, on the order of $20-25 \%$, at the time of ID ligament rupture.

Two additional cases with different initial cracks were also simulated, and the results are summarized in Table 3.2. In case 2, the two initial cracks were modeled with $2 c+b=12.7 \mathrm{~mm}$, $\mathrm{a} / \mathrm{h}=70$, and $\mathrm{b}=0.13 \mathrm{~mm}$. The FEM calculations estimated an ID ligament rupture pressure of 31.51 $\mathrm{MPa}$, which is well correlated with the experimental value of $33.8 \mathrm{MPa}$. In case 3, two through-wall initial cracks were modeled with $2 \mathrm{c}+\mathrm{b}=12.7 \mathrm{~mm}, \mathrm{a} / \mathrm{h}=100$, and $\mathrm{b}=0.25 \mathrm{~mm}$. In this case, the crack initiation in the axial ligament is predicted to start at $3.8 \mathrm{MPa}$, which is well below the corresponding applied pressure of $15.86 \mathrm{MPa}$ for case 1 . Note that case 1 has the same initial crack geometry as case 3, but they differ in that a/h is $72 \%$ for case 1 and $100 \%$ for case 3 . It is also predicted that the axial ligament rupture pressure for case 3 is $4.1 \mathrm{MPa}$, which is also well below the axial ligament rupture pressure for case 1 .

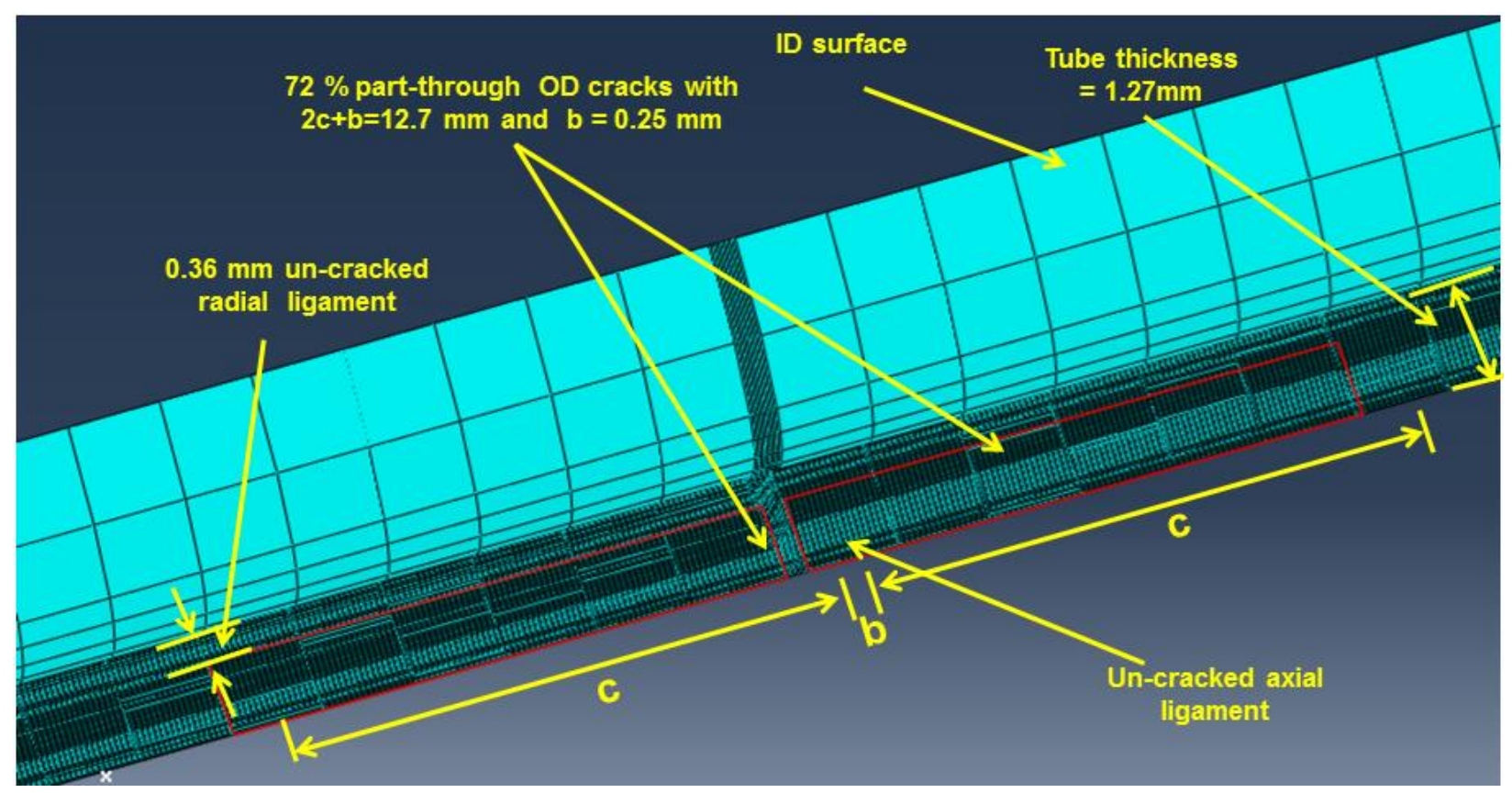

Figure 3. 13 FEM model of 22.2-mm (7/8-in.) OD tube with two interacting initial cracks 

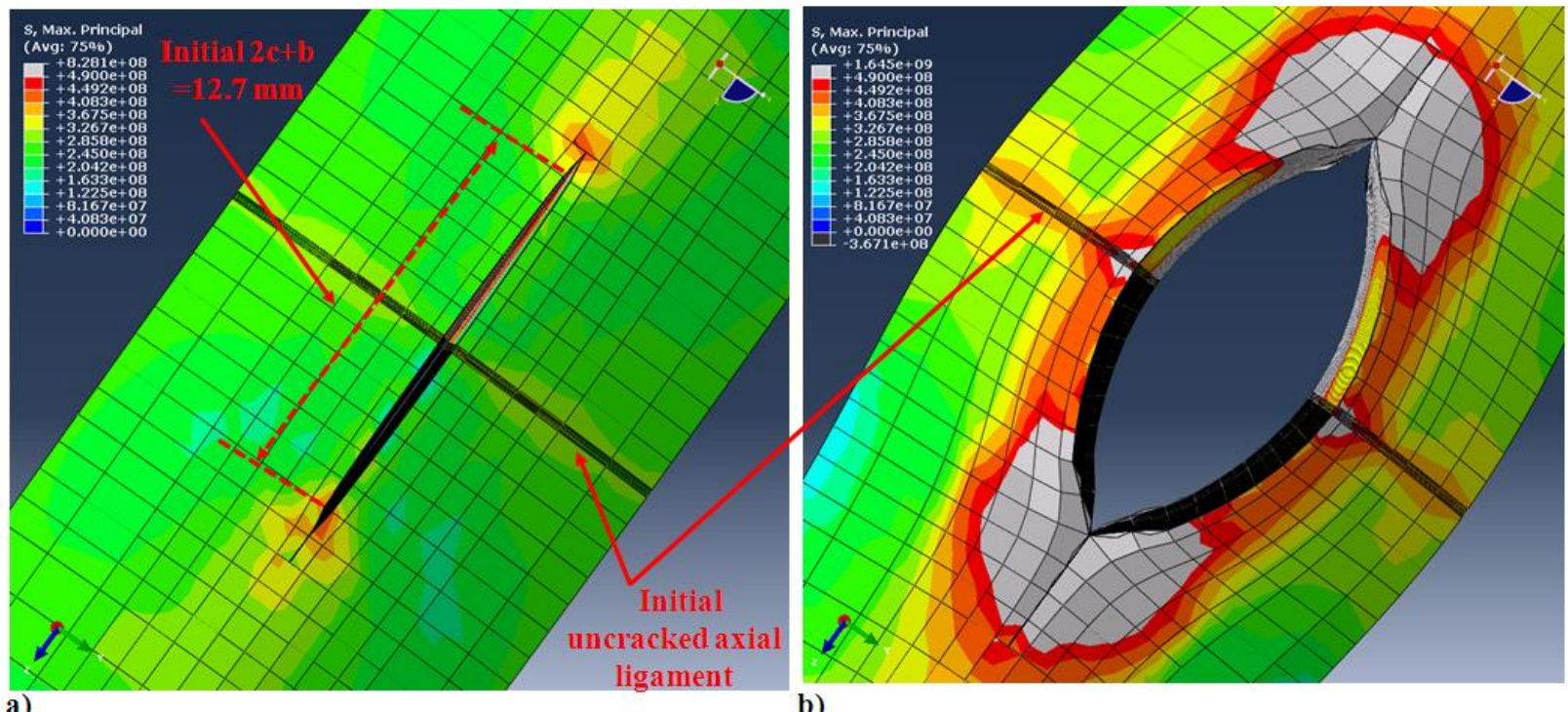

a)

b)

Figure 3. 14 Shape of the OD surface and maximum principal stress distribution for case 1 at (a) ID ligament rupture pressure (30.97 $\mathrm{MPa}$ ) and (b) final burst pressure (31.22 $\mathrm{MPa}$ )

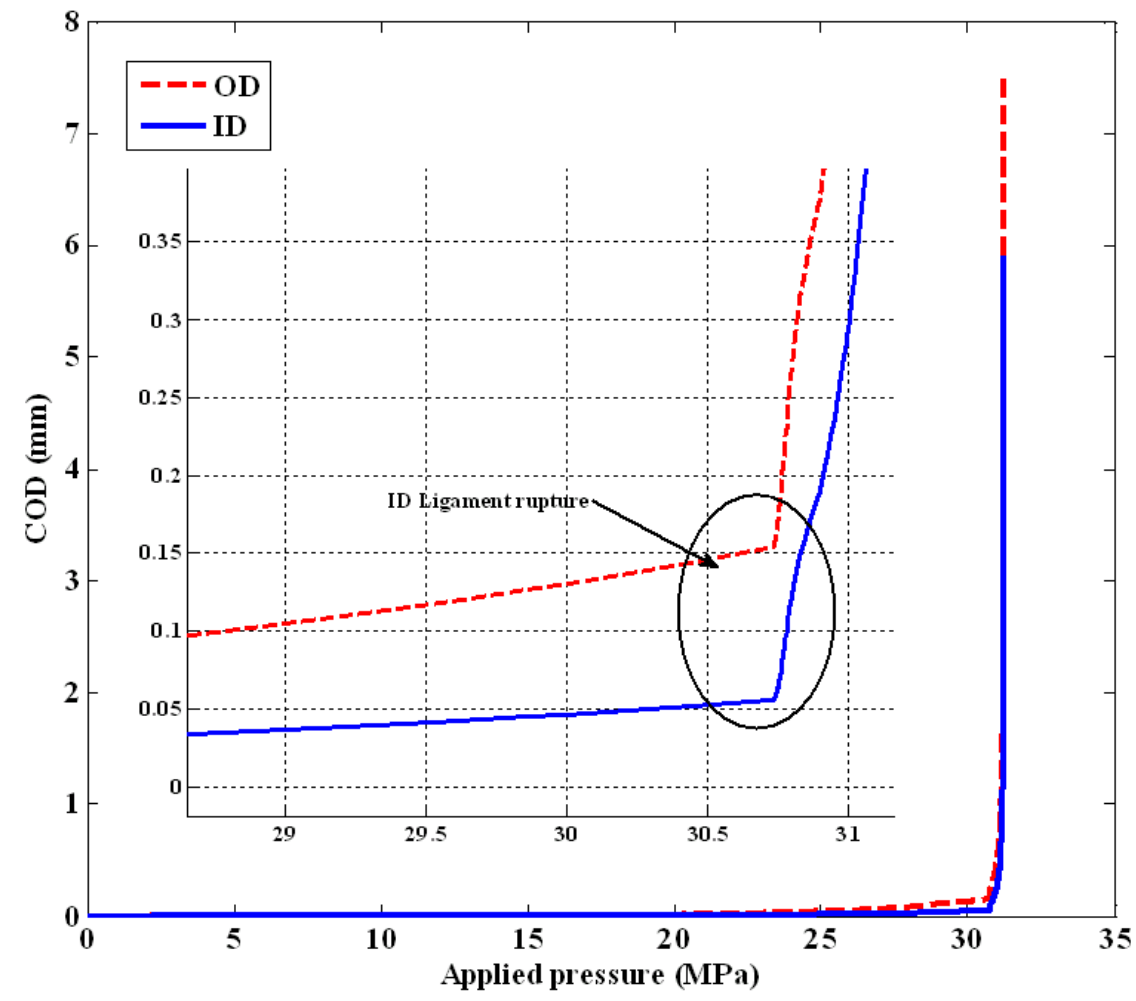

Figure 3. 15 Estimated COD with respect to applied pressure at the OD and ID surface for case-1 tube (see Table 3.2) with $2 c+b=12.7 \mathrm{~mm}, a / h=72$, and $b=0.25 \mathrm{~mm}$ 


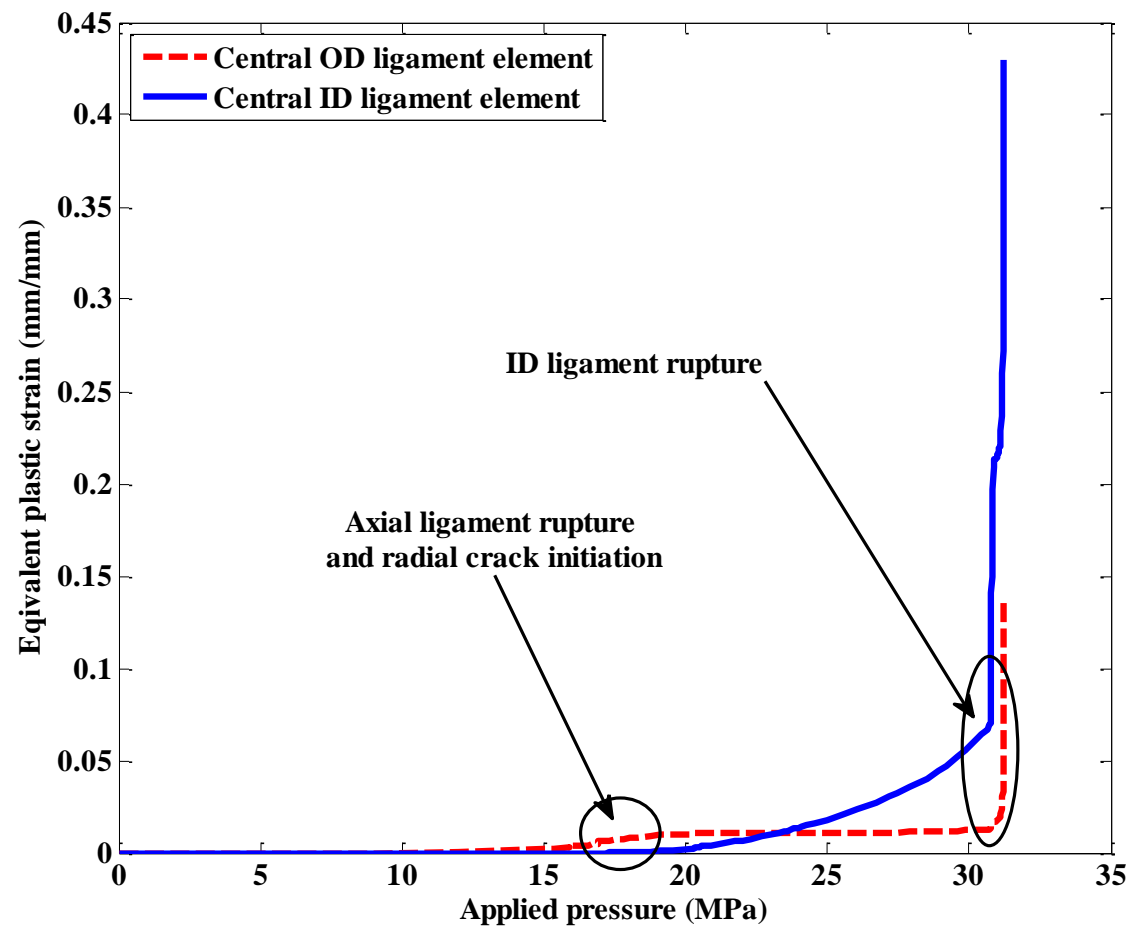

Figure 3. 16 Estimated equivalent plastic strain with respect to applied pressure at the OD and ID surface for case-1 tube (see Table 3.2) with $2 c+b=12.7 \mathrm{~mm}, a / h=72$, and $b=0.25 \mathrm{~mm}$

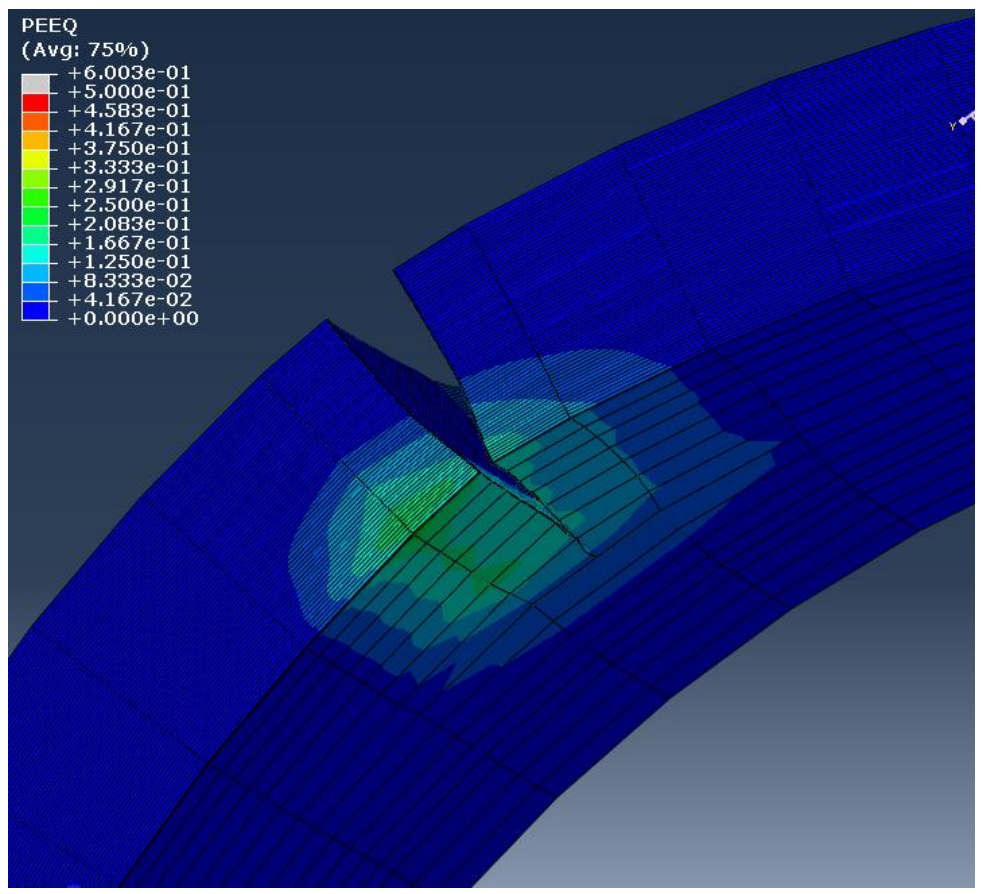

Figure 3. 17 Distribution of equivalent plastic strain at 30.97 MPa (radial ligament rupture pressure) for case-1 tube (see Table 3.2) with $2 c+b=12.7 \mathrm{~mm}, a / h=72$, and $b=0.25 \mathrm{~mm}$ 
Table 3.2 XFEM and experimental results for three cases of crack coalescence model

\begin{tabular}{|c|c|c|c|c|c|c|}
\hline \multirow[b]{2}{*}{$\begin{array}{l}\text { Case } \\
\text { No. }\end{array}$} & \multirow[b]{2}{*}{$\begin{array}{l}\text { Initial crack } \\
\text { description }\end{array}$} & \multicolumn{4}{|c|}{ XFEM model results (MPa) } & \multirow{2}{*}{\begin{tabular}{|c}
$\begin{array}{c}\text { Experiment } \\
\text { (MPa) }\end{array}$ \\
Radial \\
ligament \\
rupture \\
pressure
\end{tabular}} \\
\hline & & $\begin{array}{l}\text { Axial } \\
\text { ligament } \\
\text { crack } \\
\text { initiation } \\
\text { pressure }\end{array}$ & $\begin{array}{c}\text { Axial } \\
\text { ligament } \\
\text { rupture } \\
\text { pressure }\end{array}$ & $\begin{array}{c}\text { Radial } \\
\text { ligament } \\
\text { rupture } \\
\text { pressure }\end{array}$ & $\begin{array}{l}\text { Burst } \\
\text { pressure }\end{array}$ & \\
\hline 1 & $\begin{array}{c}\mathrm{a} / \mathrm{h}=72 \% \\
2 \mathrm{c}+\mathrm{b}=12.7 \\
\mathrm{~b}=0.25\end{array}$ & 15.86 & 16.81 & 30.97 & $\begin{array}{l}31.2 \\
2\end{array}$ & 33.8 \\
\hline 2 & $\begin{array}{c}\mathrm{a} / \mathrm{h}=70 \% \\
2 \mathrm{c}+\mathrm{b}=12.7 \\
\mathrm{~b}=0.13\end{array}$ & 14.98 & 15.14 & 31.51 & $\begin{array}{l}31.7 \\
1\end{array}$ & 33.8 \\
\hline 3 & $\begin{array}{c}\mathrm{a} / \mathrm{h}=100 \% \\
2 \mathrm{c}+\mathrm{b}=12.7 \\
\mathrm{~b}=0.25\end{array}$ & 3.8 & 4.1 & NA & $\begin{array}{l}22.3 \\
02\end{array}$ & NA \\
\hline
\end{tabular}

\subsection{Conclusion}

Multiple XFEM models were developed to predict crack initiation and propagation in Alloy 600 SG tubes with persisting crack(s). The results are compared with the experimental results available from the NRC-supported tube integrity program and conducted at ANL. The XFEM predicted rupture and burst pressure results agreed well with available experiment results at room temperature. This exercise shows that the XFEM technique can effectively be used to model propagating cracks until SG tube rupture under design-basis accident conditions. A ssimilar technique may be useful to model stress corrosion cracking and or fatigue cracks, which is one of our future tasks. 


\section{Summary of Other Ongoing Works}

The ongoing works on other subtasks are summarized below.

\subsection{Room-temperature fatigue testing of 316 SS base metal}

As one of the subtasks, 316 SS base metal is being fatigue tested in air at room temperature to estimate baseline strain (stress) versus life. All these fatigue tests are strain controlled. From these test results the baseline strain ratcheting behavior and hardening parameter will be estimated. Multiple tests are planned with different strain amplitudes. To date, two specimens have been fatigue tested under a strain amplitude of $0.5 \%$ and strain rate of $0.001 / \mathrm{s}(0.1 \% / \mathrm{s})$. Figure 4.1 shows a typical hysteresis plot estimated by using extensometer-based strain and load cell measurements. This figure shows the initial stress hardening and then softening of the material.

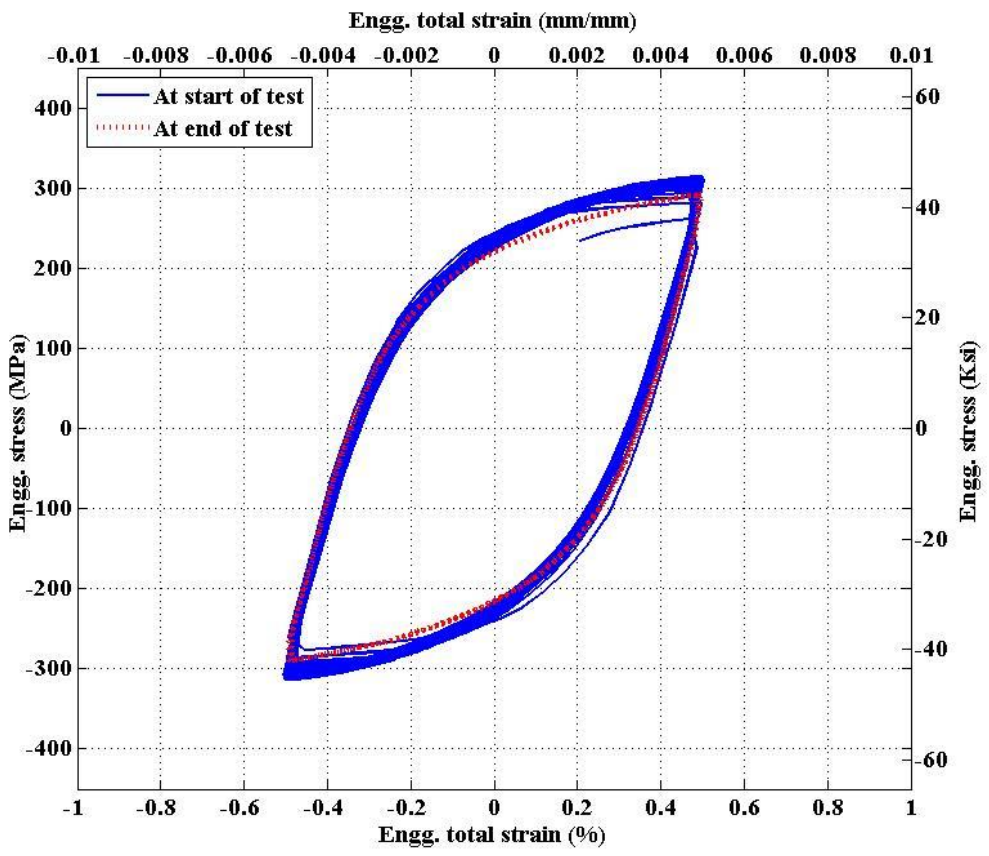

Figure 4.1 Extensometer-measurement-based hysteresis plot at the start and end of test

\subsection{Mechanistic modeling of room-temperature fatigue of 316 SS base metal}

Another subtask in mechanistic-based environmental fatigue modeling has been initiated to model the room-temperature fatigue behavior by FEM. The aim of this subtask is not only to estimate the fatigue life of material at room temperature but also to develop a FEM model that is sufficiently representative to capture real physical behavior, such as strain ratcheting, softening, hardening, etc. Figure 4.2 shows a typical FEM model of a 316 SS base metal specimen. Figure 4.3 shows an estimated hysteresis plot from a preliminary FEM analysis assuming isotropic hardening. A future subtask is to establish a cyclic hardening model with a user subroutine that can duplicate the measured stress-strain hysteresis behavior. 


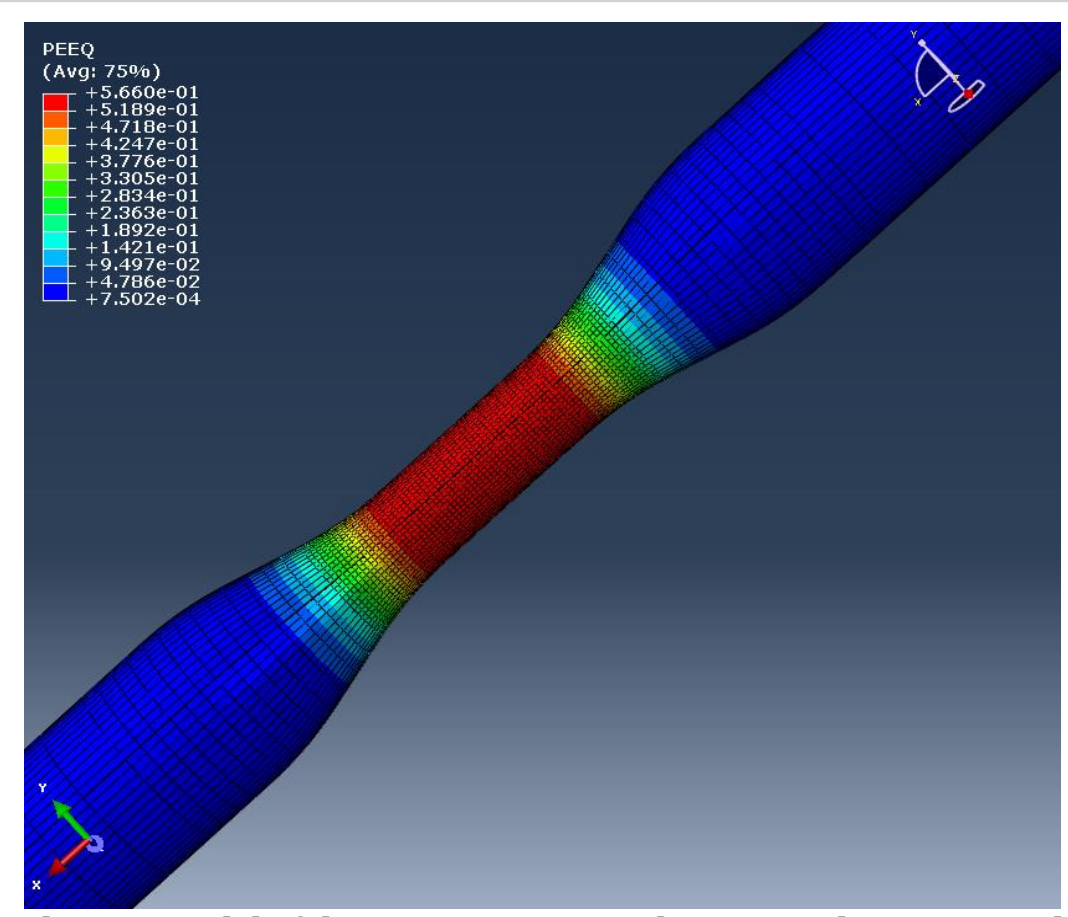

Figure 4.2 Finite element model of the 316 SS specimen showing preliminary results of accumulated effective plastic strain (absolute scale) field distribution

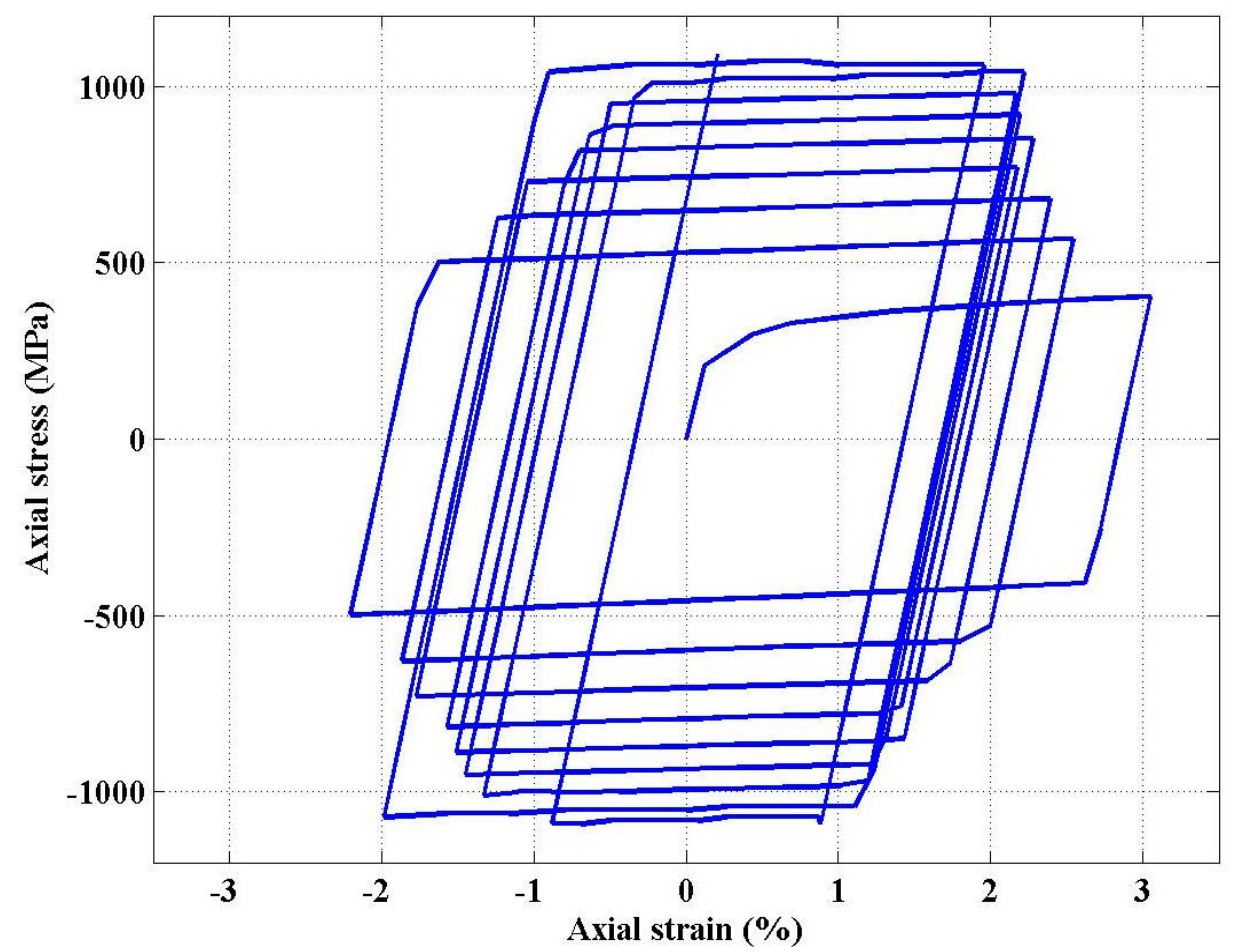

Figure 4.3 Hysteresis plot estimated from a preliminary FEM model assuming stress hardening 


\subsection{Fabrication of specimen with similar metal weld plates}

As one of the experimental subtasks, a base metal specimen of $316 \mathrm{SS}$ welded to $316 \mathrm{SS}$ is being fabricated. Figure 4.4 shows the top view of the section of the welded plates, whereas Figure 4.5 shows a cross section of the plate, including the V-weld shape. Using these welded plates, we will fabricate multiple specimens either along or across the heat-affected zone of the weld.

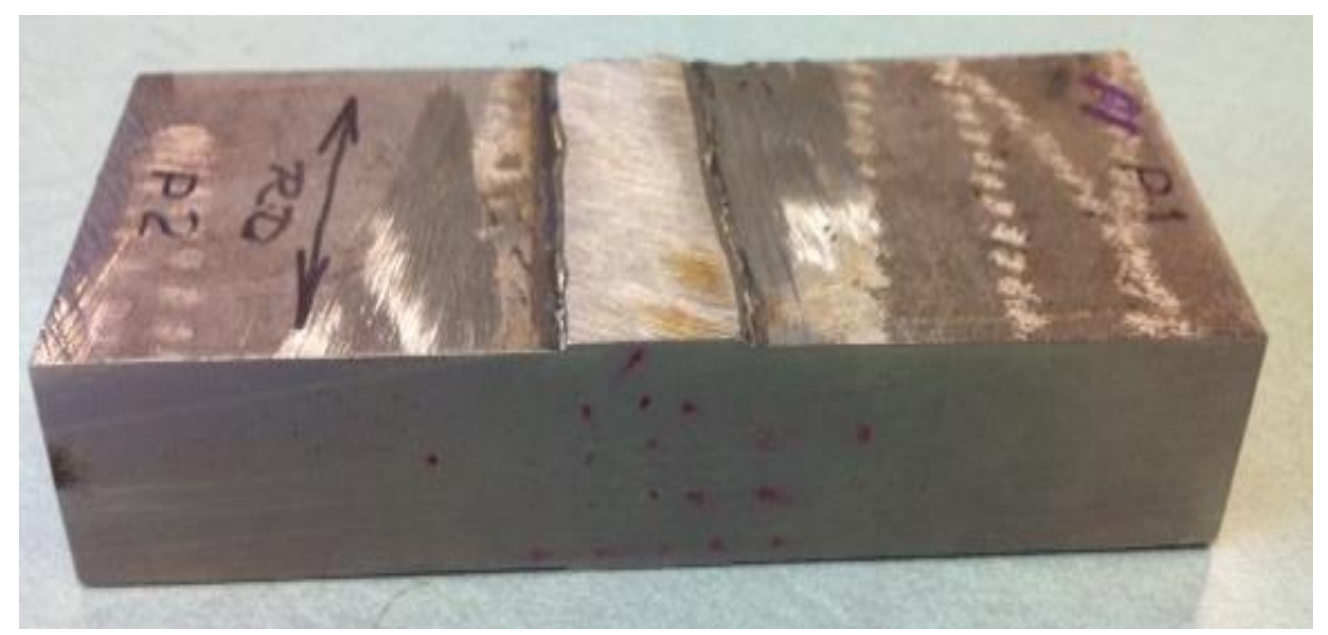

Figure 4.4 Top view of 316 SS-316 SS welded plate

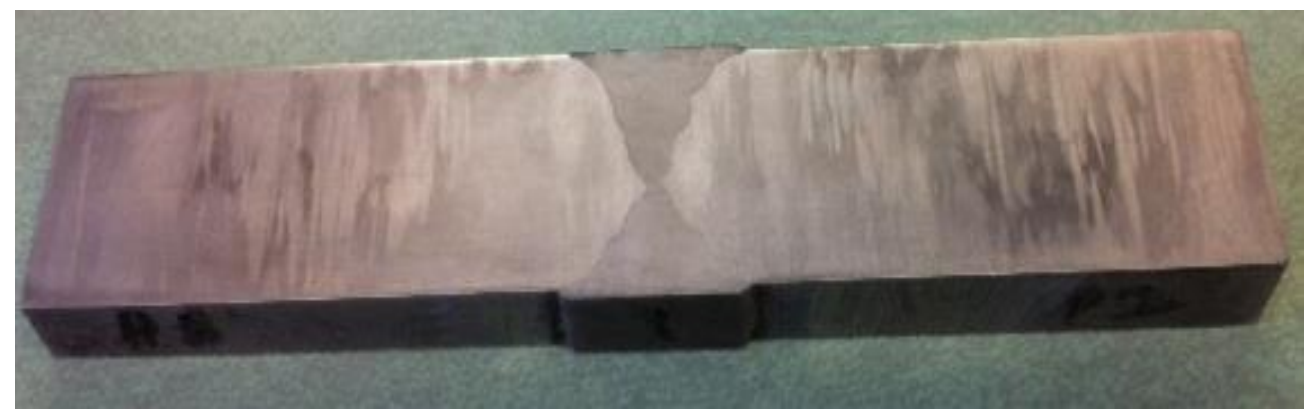

Figure 4.5 Cross section of 316 SS-316 SS welded plate

\subsection{Characterization and modeling of similar metal weld residual stress}

Significant residual stresses can be generated during the welding process. These stresses may lead to SCC in the LWR environment. In developing mechanistic models, the effects of these residual stresses need to be included. Figure 4.6 shows a typical example of residual stress distribution at the weld cross section. These residual stresses were measured for the 316SS316SS metal weld plate by Lambda Research Inc. in Cincinnati, Ohio [21], using X-ray diffraction. Figure 4.6 indicates substantial compressive residual stress at the center of the weld and tensile stress at the bottom of the weld. Comparing these results with the stress-strain curve shown in Figure 2.5 and assuming that the elastic properties of base metals holds good in the heat-affected zone, we concluded that the residual strain is well above the $0.2 \%$ offset yield 
strain. These preliminary results suggest that proper care has to be taken of residual stresses in developing mechanistic models.

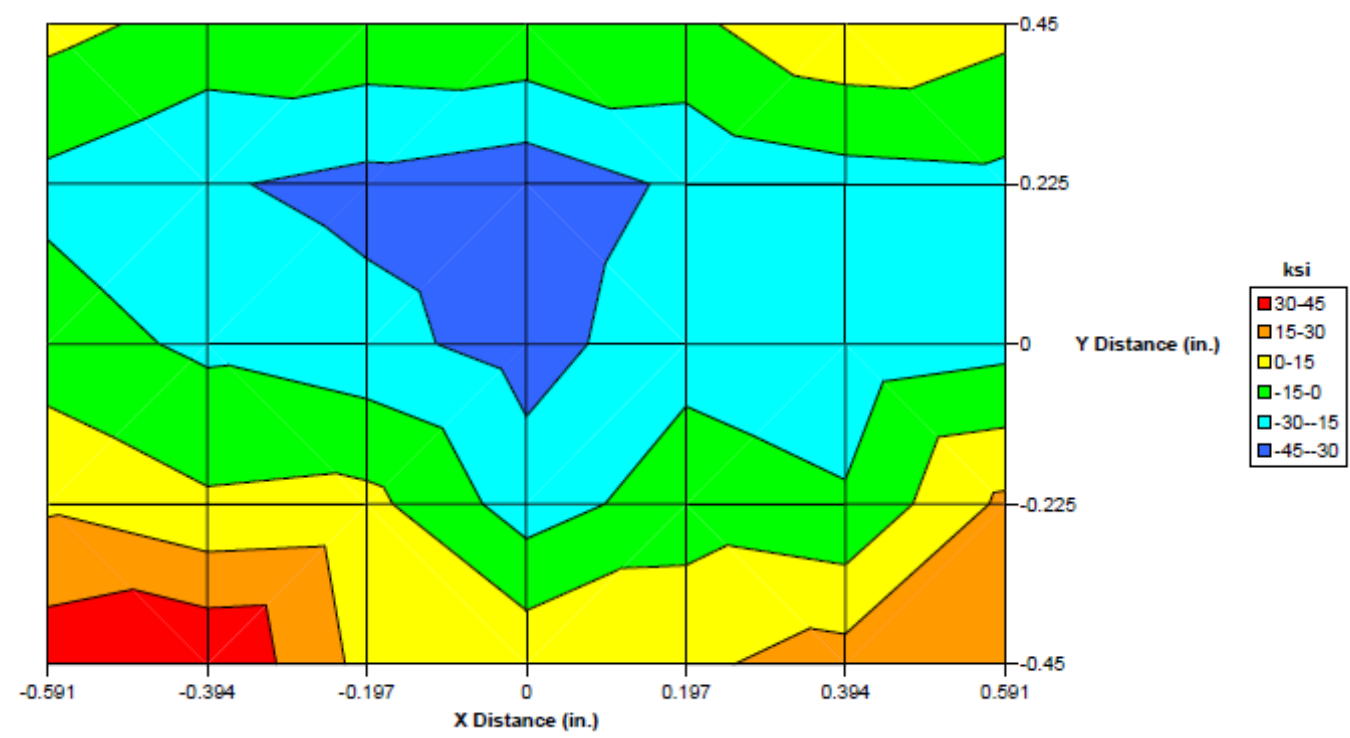

Figure 4.6 Example of residual stress profile at the 316SS-316SS plate weld cross section

\subsection{Conclusion}

In this brief summary report, the ongoing research activities related to both mechanistic modeling and experimental activities are summarized with some representative examples. The results shown are preliminary, and hence, no firm conclusions can be drawn. 


\section{Summary and future work}

This report on the progress in the LWR environmentally assisted fatigue program can be summarized as below:

a) Room-temperature tensile testing of $316 \mathrm{SS}$ base metal for reactor coolant system: Tensile tests with 316 SS base metal were conducted at two strain rates. The details of these tests are discussed in Section 2. The resulting material properties not only will be used in the development of a mechanistic-based finite element model but also as baseline input for future test parameters.

b) Development of propagating crack model using extended finite element techniques: The details of the approach are discussed in Section 3. The modeling technique is demonstrated through simulating crack initiation and propagation in steam generator tubes at room temperature but can easily be extended to design-basis and severe accident conditions. The results were also validated against the experimental results available through the NRC-sponsored tube integrity program at ANL.

In Section 4, other ongoing tasks under the LWR environmentally assisted fatigue program are discussed through representative examples.

Under the experimental tasks, the following is planned in the near future:

a) Complete the room-temperature fatigue testing of $316 \mathrm{SS}$ base metals specimens

b) Initiate elevated-temperature tensile and fatigue testing of $316 \mathrm{SS}$ base metal specimens

c) Finish fabrication of $316 \mathrm{SS}-316 \mathrm{SS}$ similar metal weld specimens

d) Initiate tensile and fatigue testing of $316 \mathrm{SS}-316 \mathrm{SS}$ similar metal weld specimens

Under the mechanistic modeling tasks, the following work is planned in the near future:

a) Develop cyclic plasticity model and fatigue life estimation of $316 \mathrm{SS}$ base metal using direct cycle and stabilized cycle approach

b) Use XFEM to develop mechanistic based stress-life $(\mathrm{S} \sim \mathrm{N})$ curve

c) Develop mechanistic model of $316 \mathrm{SS}-316 \mathrm{SS}$ similar metal weld specimens 


\section{References}

1. American Society for Testing and Materials, "Standard test methods for tensile testing of metallic materials," ASTM, E8/E8M-11 (2012).

2. American Society for Testing and Materials, "Standard practice for strain-controlled fatigue testing,", ASTM, E606-04 (2012).

3. Babuska, I., Caloz, G., and Osborn, J., "Special finite element methods for a class of second order elliptic problems with rough coefficients." SIAM Journal on Numerical Analysis 31: 945-981 (1994).

4. Melenk, J., and Babuska, I., "The partition of unity finite element method: Basic theory and applications," Computer Methods in Applied Mechanics and Engineering, 39: 289314 (1996).

5. Osher, S., and Sethian, J. A., "Fronts propagating with curvature-dependent speed: Algorithms based on Hamilton-Jacobi formulations," Journal of Computational Physics 79: 12-49 (1988).

6. Sethian, James A., Level Set Methods and Fast Marching Methods : Evolving Interfaces in Computational Geometry, Fluid Mechanics, Computer Vision, and Materials Science, Cambridge: Cambridge University Press (1999).

7. Belytschko, T., and T. Black, "Elastic crack growth in finite elements with minimal remeshing," International Journal for Numerical Methods in Engineering, 45: 601-620 (1999).

8. Sukumar, N., Moes, N., Moran, B., and Belytschko, T., "Extended finite element method for three-dimensional crack modeling," International Journal for Numerical Methods in Engineering 48 (11), 1549-1570 (2000).

9. Sukumar, N., Chopp, D. L., Moes, N., Belytschko, T., "Modeling holes and inclusions by level sets in the extended finite-element method," Computer Methods in Applied Mechanics and Engineering 190(46-47): 6183-6200 (2001).

10. Sukumar, N., Chopp, D. L., Moran, B., "Extended finite element method and fast marching method for three dimensional fatigue crack propagation," Engineering Fracture Mechanics 70(1): 29-48 (2003).

11. Chessa J., "The extended finite element method for free surface and two phase flow problems," Ph.D. Thesis, Northwestern University, (2002).

12. Chessa, J., Belytschko, T., "An enriched finite element method for axisymmetric twophase flow with surface tension," Journal of Computational Physics 58: 2041-2064 (2003).

13. Chopp, D., Sukumar, N., "Fatigue crack propagation of multiple coplanar cracks with the coupled extended finite element/fast marching method," International Journal of Engineering Science 41(8): 845-869 (2003).

14. Sukumar, N., Chopp, D. L., Bechet, E., Moes, N., "Three-dimensional non-planar crack growth by a coupled extended finite element and fast marching method," International Journal for Numerical Methods in Engineering, 76(5): 727-748 (2008). 
15. Shi, J., Chopp, D., Lua, J., Sukumar, N., Belytschko. T., “ABAQUS implementation of extended finite element method using a level set representation for three-dimensional fatigue crack growth and life predictions," Engineering Fracture Mechanics 77: 28402863 (2010).

16. Bordas, S. P. A., Natarajan, S., Kerfriden, P.,, Augarde, C. E., Mahapatra, D. R., Rabczuk, T., Dal Pont, S., "On the performance of strain smoothing for quadratic and enriched finite element approximations (XFEM/GFEM/PUFEM)," International Journal for Numerical Methods in Engineering 86: 637-666 (2011).

17. Dassault Systèmes Simulia Corp., ABAQUS 6.11 User Manual (2011).

18. Bakhtiari, S., Kasza, K. E., Kupperman, D. S., Majumdar, S., Park, J. Y., Shack, W. J., Diercks, D. R.,Second U.S. Nuclear Regulatory Commission International Steam Generator Tube Integrity Research Program - Final Project Summary Report, NUREG/CR-6804 (ANL-02/28) (2003).

19. Elices, M., Guinea, G. V., Gomez, J., Planas, J., "The cohesive zone model: Advantages, limitations and challenges," Engineering Fracture Mechanics 69: 137-163 (2002).

20. Bonifaz, E. A., "Cohesive zone modeling to predict failure processes," Canadian Journal on Mechanical Science and Engineering 2: $42-53$ (2011).

21. Lambda Technologies, http://www.lambdatechs.com/index.html. 
This page intentionally left blank 



\section{Argonne}

Nuclear Engineering Division

Argonne National Laboratory

9700 South Case Avenue

Argonne, IL 60439

www.anl.gov 